\title{
Evaluation of Dynamic Load Factors for a High-Speed Railway Truss Arch Bridge
}

\author{
Ding Youliang and Wang Gaoxin \\ The Key Laboratory of Concrete and Prestressed Concrete Structures of Ministry of Education, \\ Southeast University, Nanjing 210096, China
}

Correspondence should be addressed to Ding Youliang; civilchina@hotmail.com

Received 20 May 2016; Revised 18 August 2016; Accepted 21 August 2016

Academic Editor: Edoardo Sabbioni

Copyright (C) 2016 D. Youliang and W. Gaoxin. This is an open access article distributed under the Creative Commons Attribution License, which permits unrestricted use, distribution, and reproduction in any medium, provided the original work is properly cited.

\begin{abstract}
Studies on dynamic impact of high-speed trains on long-span bridges are important for the design and evaluation of high-speed railway bridges. The use of the dynamic load factor (DLF) to account for the impact effect has been widely accepted in bridge engineering. Although the field monitoring studies are the most dependable way to study the actual DLF of the bridge, according to previous studies there are few field monitoring data on high-speed railway truss arch bridges. This paper presents an evaluation of DLF based on field monitoring and finite element simulation of Nanjing DaShengGuan Bridge, which is a high-speed railway truss arch bridge with the longest span throughout the world. The DLFs in different members of steel truss arch are measured using monitoring data and simulated using finite element model, respectively. The effects of lane position, number of train carriages, and speed of trains on DLF are further investigated. By using the accumulative probability function of the Generalized Extreme Value Distribution, the probability distribution model of DLF is proposed, based on which the standard value of DLF within 50-year return period is evaluated and compared with different bridge design codes.
\end{abstract}

\section{Introduction}

During the bridge design, static load effect should multiple dynamic load factor (DLF) for consideration of the dynamic effects. Thus, accurate evaluation of the DLF will lead to safe and economical designs of new bridges and provide valuable information for condition assessment of existing bridges. However, determining the DLF is a rather complicated problem because of the interaction between the bridge and moving vehicles.

Most studies using the analytical approach have been conducted to investigate the bridge-vehicle interaction and estimate the DLF. For example, Paultre et al. [1] presented an extensive review of early studies conducted on bridge dynamics and the evaluation of the dynamic amplification factor (DAF). McLean and Marsh [2] provided a synthesis that summarizes the important knowledge and findings with respect to vehicular dynamic load effects on highway bridges. Deng et al. [3] calculated the reliability-based dynamic load allowance for capacity rating of prestressed concrete girder bridges. Ding et al. [4] evaluated the dynamic vehicle axle loads on bridges with different surface conditions. With the development of field testing technology, field tests have proven to be the best available approach to investigate the actual bridge-vehicle interaction to estimate the DLF. For example, Demeke et al. [5] evaluated the dynamic loads on a skew box girder continuous bridge using field test and modal analysis. Nassif and Nowak [6] carried out the research of dynamic load for girder bridges under normal traffic by field measurement. Miyamoto [7] carried out the field tests for remaining life and load carrying capacity assessment of concrete bridges. Park et al. [8] studied the influence of road surface roughness on dynamic impact factor of bridge by full-scale dynamic testing. Furthermore, recent years have seen a growing trend in the application of probabilistic approaches in the study of DLF using long-term monitoring results with the aid of structural health monitoring system. For example, Caprani [9] investigated the lifetime highway bridge traffic load effect from a combination of traffic states allowing for dynamic amplification using the Generalized 


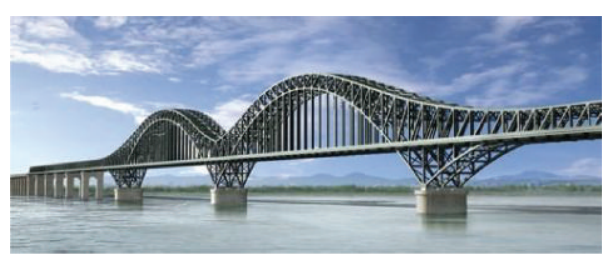

(a) View of the Nanjing DaShengGuan Bridge

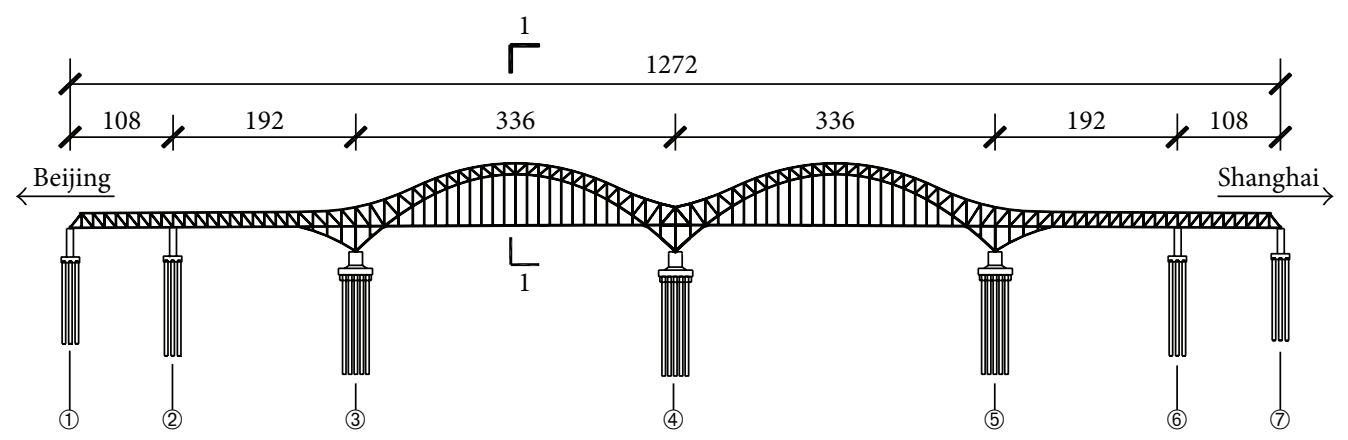

(b) Elevation drawing of the bridge (unit: $\mathrm{m}$ )

FIGURE 1: Nanjing DaShengGuan Bridge.

Extreme Value Distribution. Deng and Cai [10] developed the dynamic impact factor for performance evaluation of existing multigirder concrete bridges using the Gumbel distribution.

Even though the field tests had been carried out on many types of bridge structures, according to previous studies there are few field monitoring data on high-speed railway truss arch bridges. In this study, a long-term field monitoring was conducted on the Nanjing DaShengGuan Bridge to collect the dynamic responses induced by high-speed trains. Nanjing DaShengGuan Bridge is a steel truss arch bridge with the longest span throughout the world. Its $336 \mathrm{~m}$ main span and 6-track railways rank it the largest bridge with heaviest design loading among the high-speed railway bridges by far. Also the design speed of $300 \mathrm{~km} / \mathrm{h}$ of the bridge is on the advanced level in the world. Thus it is valuable to monitor the actual DLF under normal traffic conditions. The DLFs in different members of steel truss arch are measured using monitoring data and simulated using finite element model, respectively. A parametric study was further carried out to investigate the influences of lane position, number of train carriages, and speed of trains on DLF. To determine the appropriate DLF value for design purposes, a statistical analysis was finally conducted.

\section{Dynamic Strain Responses of the Bridge}

2.1. Field Monitoring System. The subject of this study is Nanjing DaShengGuan Bridge shown in Figure 1(a), which is a steel truss arch bridge with the span arrangement $(108+192+$ $2 \times 336+192+108) \mathrm{m}$. The elevation drawing of the bridge is shown in Figure 1(b). Due to the remarkable characteristics of Nanjing DaShengGuan Bridge including long span of the main girder, heavy design loading, and high speed of trains, a long-term SHM system was designed and installed on the Nanjing DaShengGuan Bridge shortly after it was opened to railway traffic. As shown in Figure 1(b), dynamic strain monitoring of steel truss arch is performed at the 1-1 cross section in the middle of the first main span of the bridge. The steel truss arch comprises chord members with box-shaped cross sections (top chord, bottom chord, and deck chord, resp.), diagonal web members with I-shaped cross sections, vertical web members, and horizontal and vertical bracings as shown in Figures 2(a) and 2(b). It can be seen from Figures 2(c)-2(f) that eight FBG strain sensors are installed on the top chord member, the diagonal web member, the bottom chord member, and the deck chord member, respectively. Sampling frequency of dynamic strain data collection is set to $50 \mathrm{~Hz}$.

2.2. Finite Element Modeling of the Bridge and Train. Although field monitoring studies remain the most dependable way to study the dynamic load factors (DLFs) of the bridge, the limited monitoring positions have restricted their extensive applications. Another method to obtain the dynamic strain responses of the whole bridge is finite element (FE) modeling method. Currently, with the advances of computer technology, FE modeling method has been widely applied to obtain results that are in good agreement with those measured from field tests. Figure 3 shows the threedimensional finite element model of the Nanjing DaShengGuan Bridge using ANSYS software. A total of 59760 nodes and 112706 elements are built in the model, 58370 of which are beam elements and 54336 of which are shell elements. The top chords, the bottom chords, the deck chords, the diagonal web members, the vertical web members, and the horizontal and vertical bracings of the steel truss arch are simulated by BEAM188 element; the diaphragm members and top plates of the steel bridge deck are simulated by SHELL181 element. Moreover, the finite element model has 7 bearings. The restraints of 7 bearings are set as follows: the middle bearing is constrained with three degrees of translational freedom 


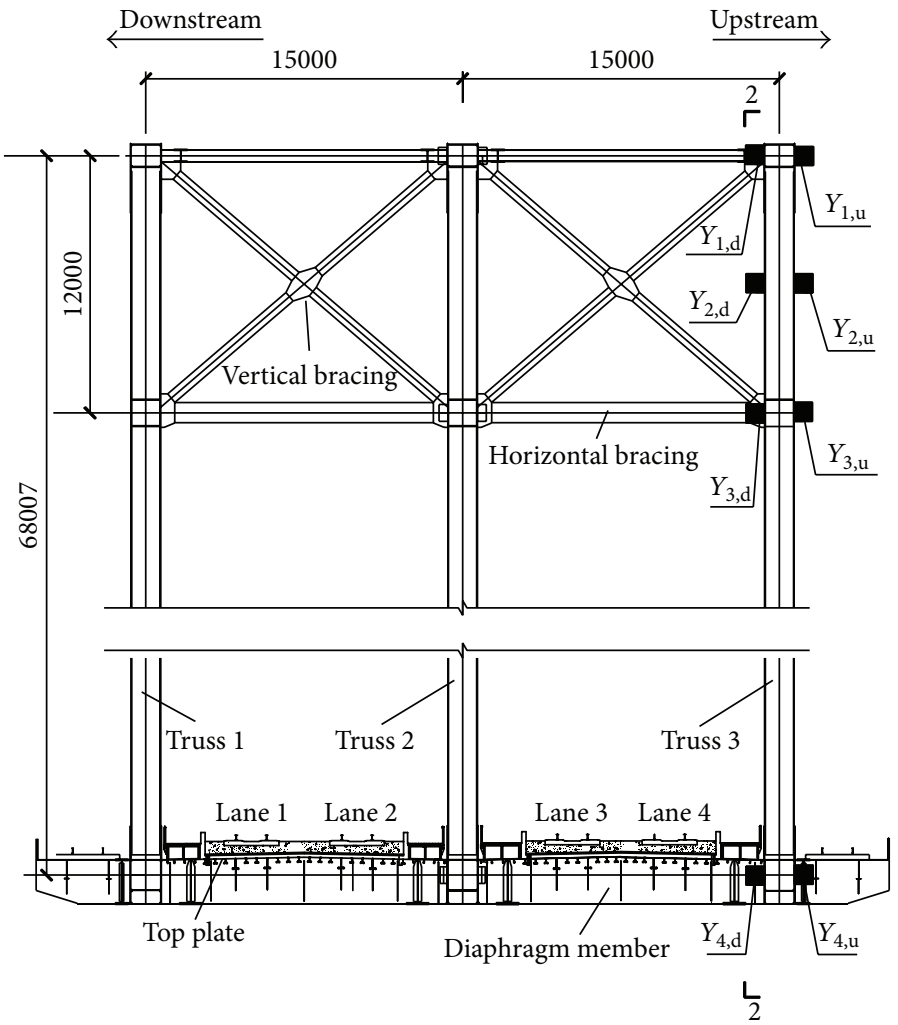

(a) 1-1 cross section of steel truss arch

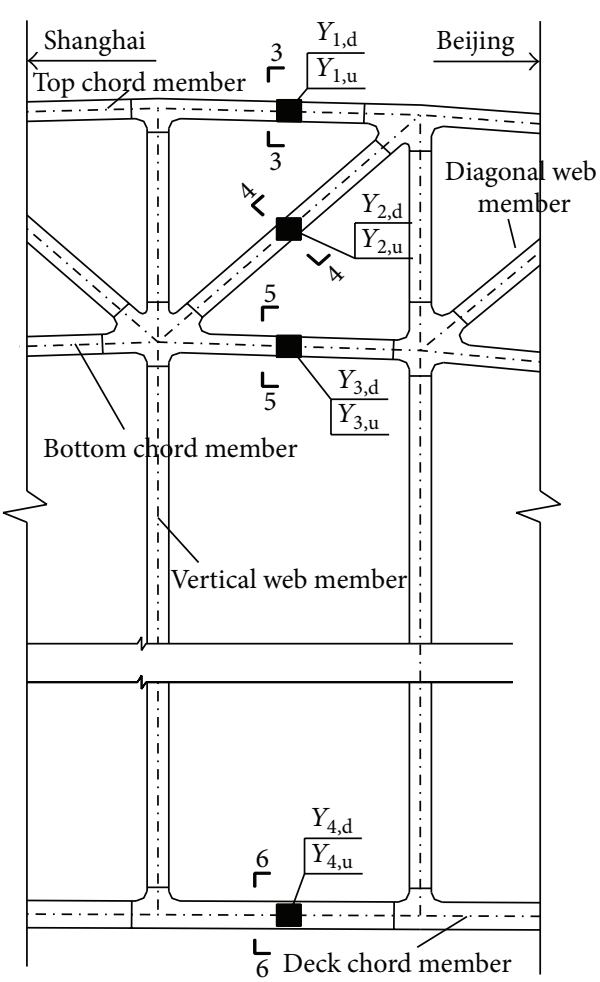

(b) 2-2 section of steel truss arch

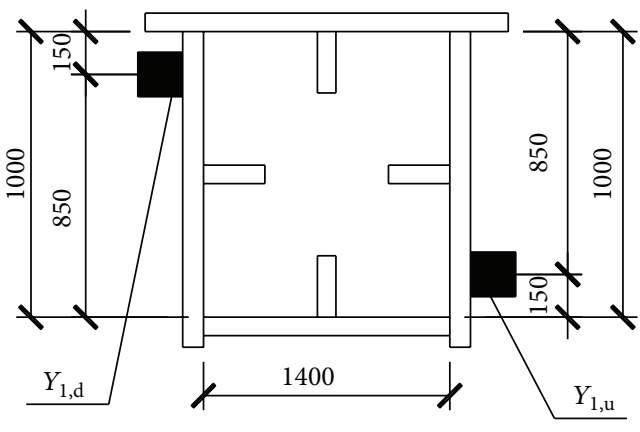

(c) 3-3 section of top chord member

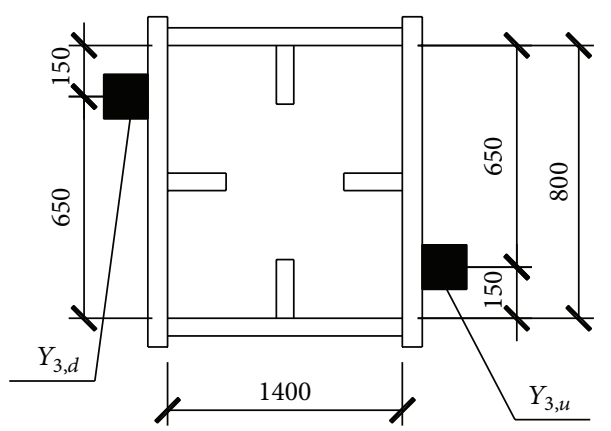

(e) 5-5 section of bottom chord member

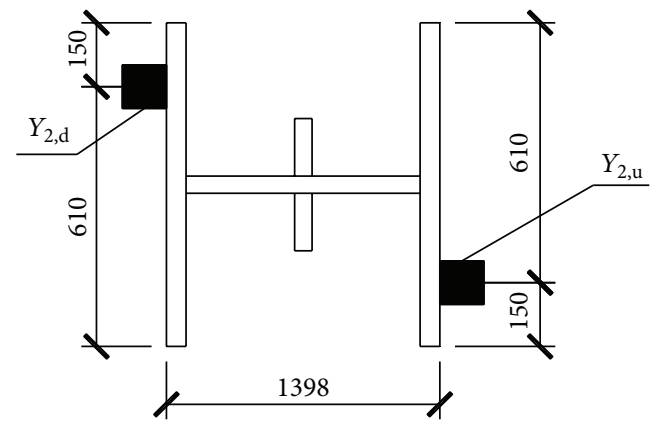

(d) 4-4 section of diagonal web member

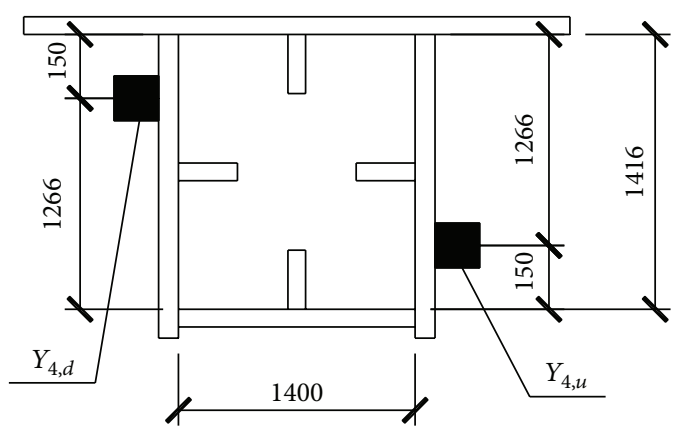

(f) 6-6 section of deck chord member

Figure 2: Location of strain sensors on the steel truss arch bridge (unit: $\mathrm{mm}$ ). 


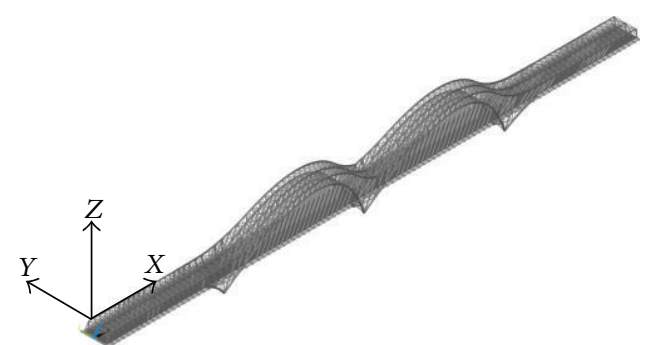

FIGURE 3: Three-dimensional FE model of Nanjing DaShengGuan Bridge.

in directions of longitudinal $X$, transverse $Y$, and vertical $Z$; the other bearings are constrained with two degrees of translational freedom in directions of transverse $Y$ and vertical $Z$. The elastic modulus and poison ratio of the steel are selected as $210 \mathrm{GPa}$ and 0.30 . The acceleration of gravity is set to $9.8 \mathrm{~m} / \mathrm{s}^{2}$. The damping ratio is set to 0.02 .

The parameters of the train loads are determined from the prototype (CRH3) of trains on the Beijing-Shanghai highspeed railway line. The train prototype is an electric multiple unit (EMU) including 8 or 16 carriages. The weight of an empty EMU is $380 \mathrm{t}$, and an EMU has a seating capacity of 601 people. Assuming that the average weight per person is $80 \mathrm{~kg}$, which is defined from China's Ministry of Railways in 2001, each carriage's weight is $G=53,510 \mathrm{~kg}$, and the vertical excitation force generated by a wheel is $F=(G / 8) \times 9.8 \mathrm{~N} / \mathrm{kg}=$ $65,549.75 \mathrm{~N}$. Because of the large length of a single carriage $(24 \mathrm{~m})$, the load model of the carriage is divided into 8 point loads, and the loads of an EMU with 8 or 16 carriages are grouped as $8 \times 8 \times F$ or $8 \times 16 \times F$. Moreover, it is supposed that the train wheels are always closely touching the surface of the bridge without deviation, so the wheels and the surface of the bridge are coupled by the compatibility of displacements and equilibrium of forces at the contact points.

2.3. Results of Dynamic Strain Responses. As for dynamic strain monitoring, each chord member or diagonal web member has two strain sensors on the downstream side and upstream side, respectively. The average values of two strain sensors are calculated to represent the axial dynamic strain of the corresponding member in the truss arch:

$$
A_{i}=\frac{S_{i, \mathrm{~d}}+S_{i, \mathrm{u}}}{2}
$$

where $S_{i, \mathrm{~d}}$ and $S_{i, \mathrm{u}}$ denote the strain data from the $i$ th strain sensors $Y_{i, \mathrm{~d}}$ and $Y_{i, \mathrm{u}}$, respectively; $A_{i}$ denotes the axial dynamic strain of the corresponding member. Figure 4 show the typical time histories of dynamic strain data $A_{1} \sim A_{4}$ when one train passed through the bridge from 9:28:47 pm to 9:29:59 pm on August 7th, 2013. Corresponding to this loading case, the simulated dynamic strain responses are obtained using FE model method. Its train load for each carriage is $535 \mathrm{kN}$; its loading position is lane 2; the number of its carriages is 8 . Figure 4 also shows the results of simulated strain responses $A_{\mathrm{s}, 1} \sim A_{\mathrm{s}, 4}$, corresponding to $A_{\mathrm{s}, 1} \sim A_{\mathrm{s}, 4}$. It can be seen that the amplitudes of monitoring strain and simulated strain are close, verifying the effectiveness of the FE modeling method. It should be mentioned that although partial trends of monitoring strain and simulated strain are not consistent, such inconsistency will not influence the calculation results of DLF, because the DLF is decided by the amplitude of strain rather than the trend of strain.

\section{Dynamic Load Factors of the Bridge}

3.1. Definition of the Dynamic Load Factor. Bakht and Pinjarkar [11] suggested the following equation for calculation of the dynamic load factor:

$$
\mathrm{DLF}=1+\mathrm{DLA}
$$

where DLF denotes the dynamic load factor, and DLA denotes the dynamic load allowance given by

$$
\mathrm{DLA}=\frac{R_{\text {dyn }}-R_{\text {stat }}}{R_{\text {stat }}},
$$

where $R_{\text {dyn }}$ denotes the maximum dynamic strain response, and $R_{\text {stat }}$ denotes the maximum static strain response.

3.2. Dynamic Load Factors from the Dynamic Strain Responses. As for the monitoring strain data, the dynamic strain data can be directly collected by strain sensors (namely $A_{i}$ ), and the static strain data can be acquired by filtering the dynamic strain data with a low-pass filter to eliminate the dynamic components of strain data. As for the simulated strain data, the dynamic and static strain data can be directly obtained using FE model method. Then $R_{\text {dyn }}$ is calculated by

$$
R_{\text {dyn }}=\max (\operatorname{abs}(M))
$$

where $M$ denotes the monitoring dynamic strain data $A_{i}$ or the simulated dynamic strain data $A_{\mathrm{s}, i} ; \operatorname{abs}(M)$ denotes the absolute value of $M$, and $\max (\operatorname{abs}(M))$ denotes the maximum value of $\operatorname{abs}(M)$. And $R_{\text {stat }}$ is calculated by

$$
R_{\text {stat }}=\max (\operatorname{abs}(Q)) \text {, }
$$

where $Q$ denotes the monitoring static strain data or the simulated static strain data; $\operatorname{abs}(Q)$ denotes the absolute value of $Q$, and $\max (\operatorname{abs}(Q))$ denotes the maximum value of $\operatorname{abs}(Q)$.

Therefore, the DLF of monitoring strain data is calculated by four steps: (i) calculate the maximum amplitude $R_{\text {dyn }}$ of monitoring dynamic strain by using (4); (ii) acquire the static strain by using the low-pass filter; (iii) calculate the maximum amplitude $R_{\text {stat }}$ of static strain data by using (5); (iv) calculate the DLF by using (2) and (3). The DLF of simulated strain data is calculated by three steps: (i) calculate the maximum amplitude $R_{\text {dyn }}$ of simulated dynamic strain by using (4); (ii) calculate the maximum amplitude $R_{\text {stat }}$ of simulated static strain by using (5); (iii) calculate the DLF by using (2) and (3).

It should be noted that an appropriate low-pass filter is important to obtain the authentic static strain data. In this study, the FIR (Finite Impulse Response) filter is used [11]. 


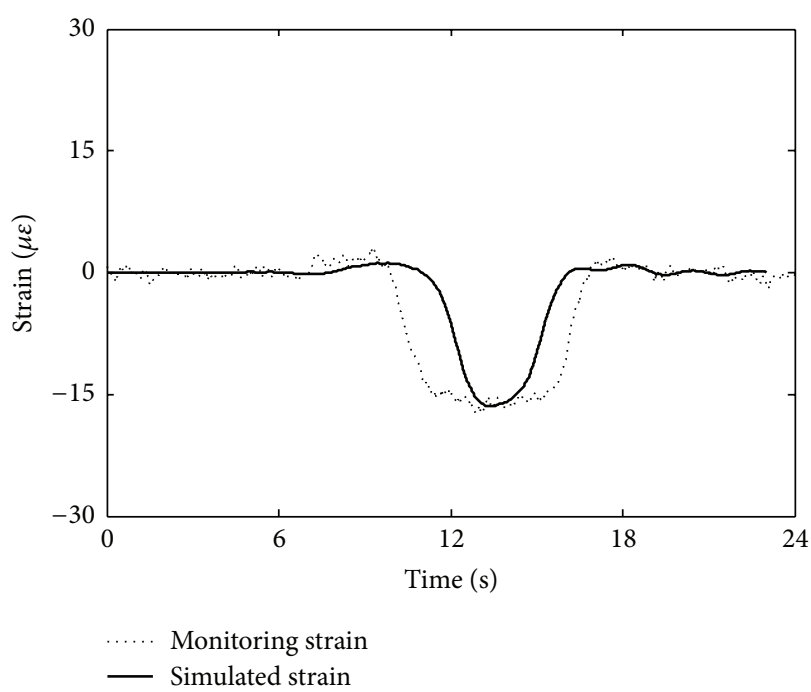

(a) $A_{1}$ and $A_{s, 1}$ of top chord member

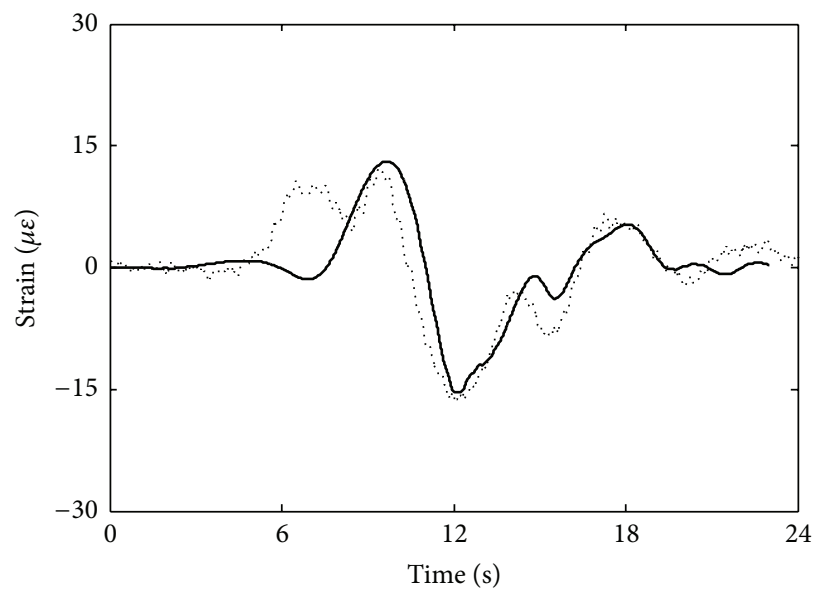

Monitoring strain

Simulated strain

(c) $A_{3}$ and $A_{\mathrm{s}, 3}$ of bottom chord member

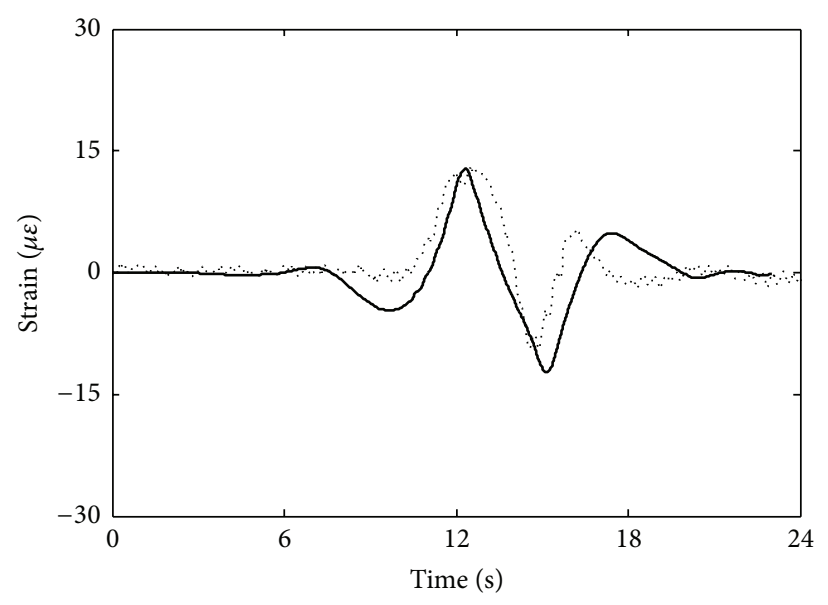

Monitoring strain

Simulated strain

(b) $A_{2}$ and $A_{\mathrm{s}, 2}$ of diagonal web member

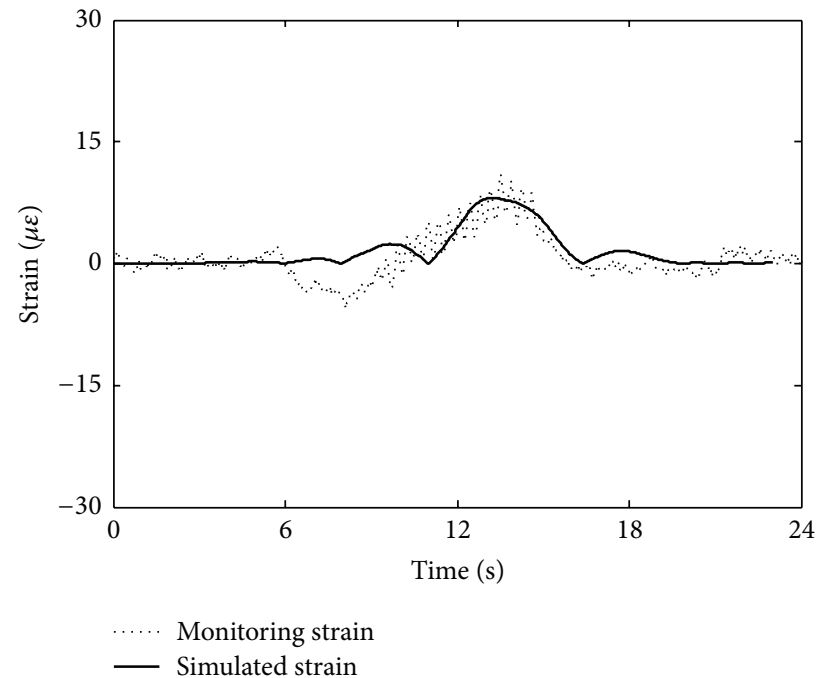

(d) $A_{4}$ and $A_{\mathrm{s}, 4}$ of deck chord member

FIGURE 4: Typical dynamic strain responses of field monitoring and FE modeling results.

The transfer function of a polynomial of $n$-order FIR filter is defined by

$$
H(z)=\sum_{i=0}^{n} b_{i} z^{-i}
$$

and its frequency response is

$$
H(\omega)=\sum_{i=0}^{n} b_{i} e^{-j \omega i}=b^{\mathrm{T}} \varphi(\omega),
$$

where $b=\left[b_{0}, b_{1}, b_{2}, \ldots, b_{n}\right]^{\mathrm{T}}$ is the coefficient vector having the filter coefficients, $\phi(\omega)=\left[1, e^{-j \omega}, \ldots, e^{-j \omega n}\right]^{\mathrm{T}}$, and $\mathrm{T}$ denotes the transpose of matrix. The coefficients of FIR filter are usually symmetric; hence they have a spectrum that exhibits a linear phase, and the response to an impulse settles to zero.
Specifically, the low-pass FIR filter is decided by four input parameters: the normalized passband edge frequency $\omega_{\mathrm{p}}$, the normalized stopband edge frequency $\omega_{\mathrm{s}}$, the allowed passband deviation $\delta_{\mathrm{p}}$, and the stopband deviation $\delta_{\mathrm{s}}$ [11]. Generally, the optimal values of four input parameters are obtained by trial-and-error approach [10]. In this study, the optimal values of four input parameters are $\omega_{\mathrm{p}}=0.004 \pi \mathrm{Hz}$, $\omega_{\mathrm{s}}=0.06 \pi \mathrm{Hz}, \delta_{\mathrm{p}}=1$, and $\delta_{\mathrm{s}}=60$ after trial-and-error approach. The static strain data are acquired by using this filter, which show good filtering effect in Figure 5.

3.3. Field Monitoring Results of Dynamic Load Factors. In this study, the dynamic strain responses of the bridge were recorded for each case having a single train traversing on the bridge. 1000 cases (a single train at a time) were selected and the computed DLFs of 1000 cases are shown in Figure 6. It is clear from the figures that the DLF is not a deterministic 


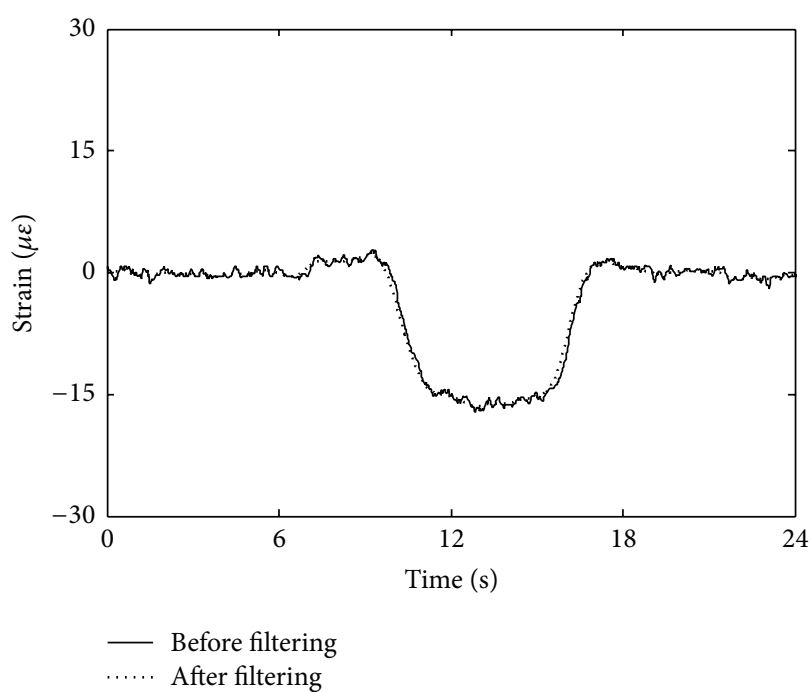

(a) $A_{1}$ of top chord member

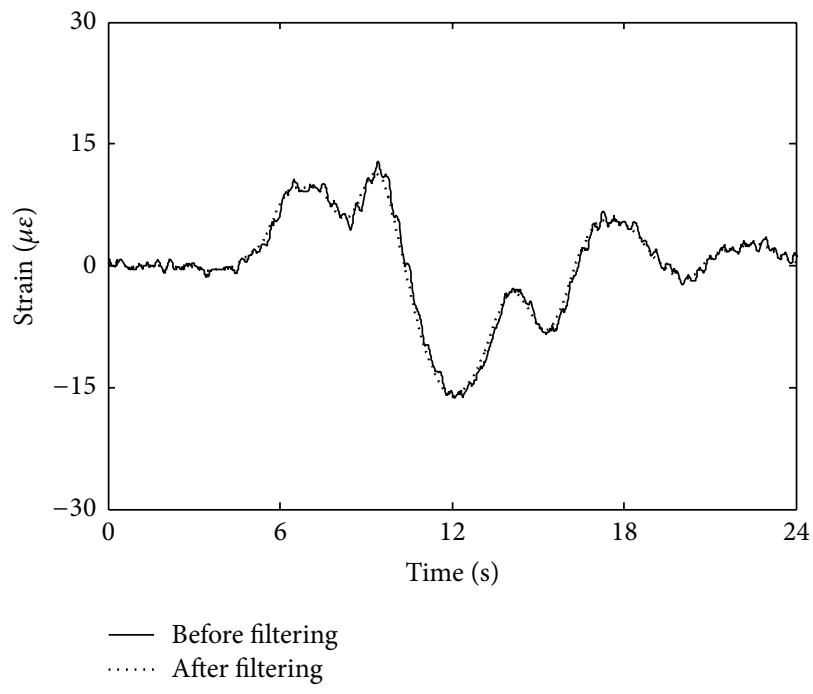

(c) $A_{3}$ of bottom chord member

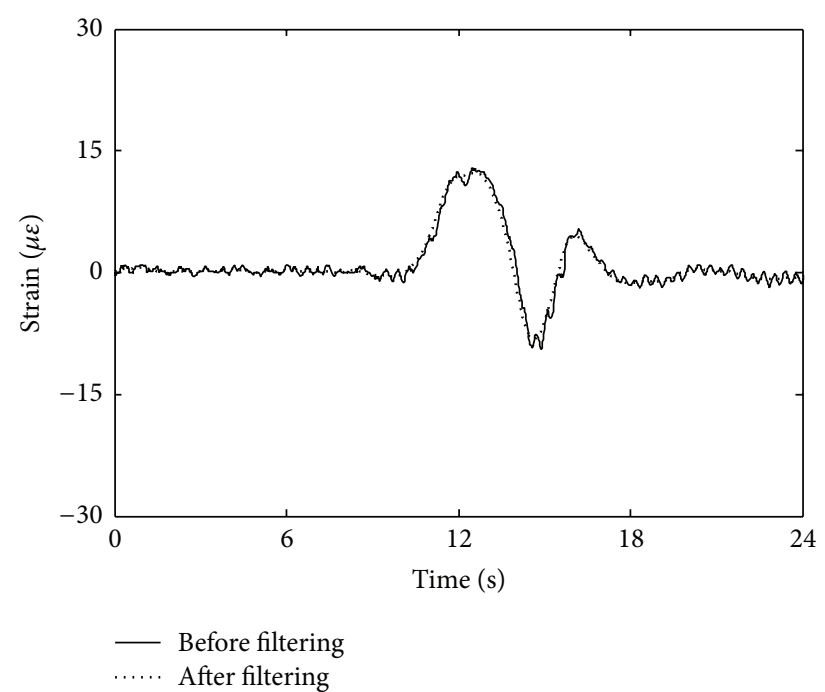

(b) $A_{2}$ of diagonal web member

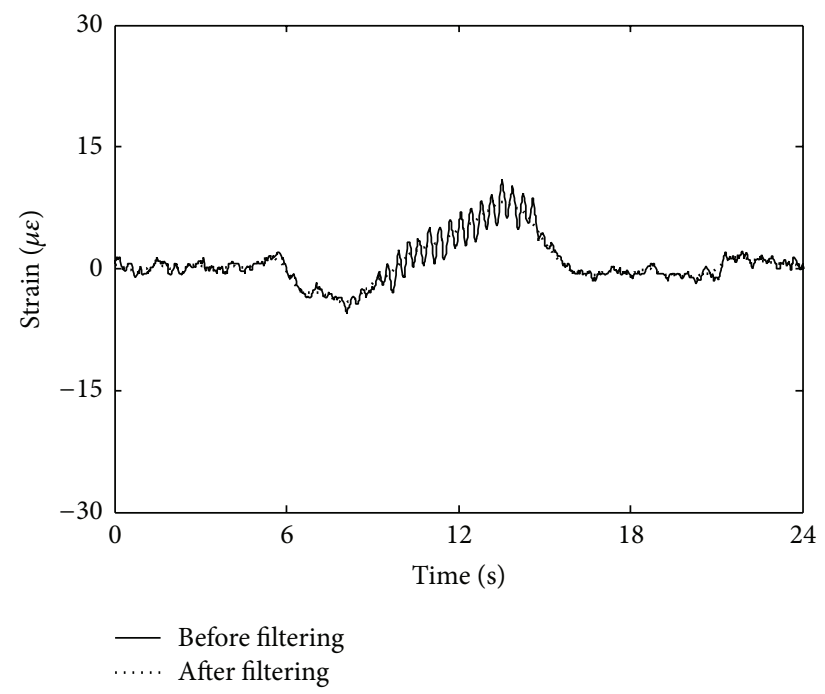

(d) $A_{4}$ of deck chord member

FIgURE 5: The dynamic and static strain responses of $A_{1} \sim A_{4}$.

quantity. Thus, the mean DLF and maximum DLF denoted by $\mathrm{AV}$ and MV are further computed and also shown in Figure 6. The mean DLF and maximum DLF computed from the bottom chord member are the largest of all, which are 1.0862 and 1.1411, respectively. And the mean DLF and maximum DLF computed from the top chord member are the smallest of all, which are only 1.0069 and 1.0106, respectively.

3.4. Dynamic Analysis Results of Dynamic Load Factors. Figure 6 shows the field monitoring results of DLFs for key members of the steel truss arch. However, only DLFs of the truss 3 as shown in Figure 2(a) have been measured. In this section, DLFs for all trusses, that is, truss 1, truss 2, and truss 3 , are obtained using the simulated strain responses with the FE modeling method. The strain data is simulated in 16 cases as shown in Table 1, and the calculation results of DLFs from truss 3 are shown in Figure 7. Moreover, Table 2 shows the monitoring and simulated AVs of the DLFs, and it can be seen that the monitoring AVs of the DLF are close to the simulated AVs of the DLFs, verifying the effectiveness of the finite element modeling method. For all 16 cases, the maximum DLF of each key member is further obtained. Thus, Figure 8 shows the maximum DLFs for key members of the truss 1 , truss 2 , and truss 3 . It can be seen that, for each truss, the maximum DLFs of the bottom chord member, the diagonal web member, the deck chord member, and the top chord member decrease successively, which is consistent with the monitoring results. Furthermore, the maximum DLFs from truss 1 and truss 3 is a little higher than those from truss 2. Thus, for three planes of truss arch, the dynamic effects induced by high-speed trains for middle truss arch are less than those for side truss arch. 


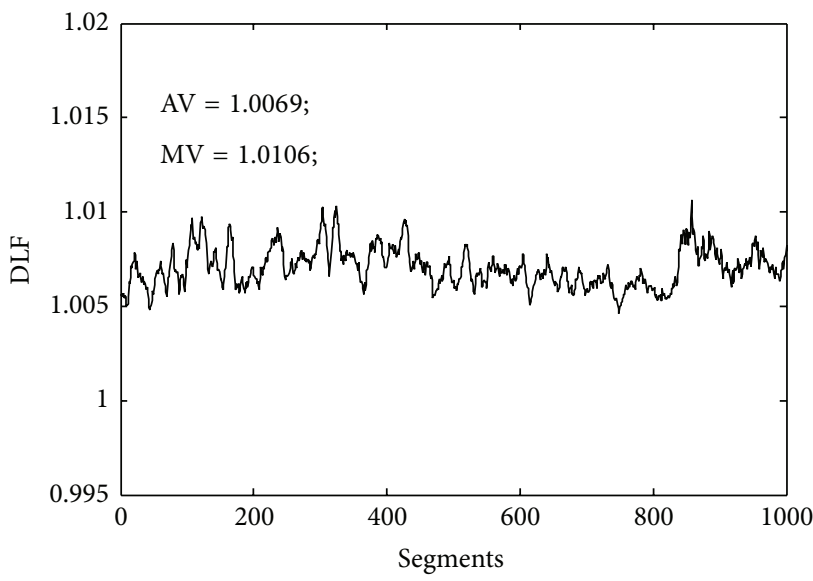

(a) The top chord member

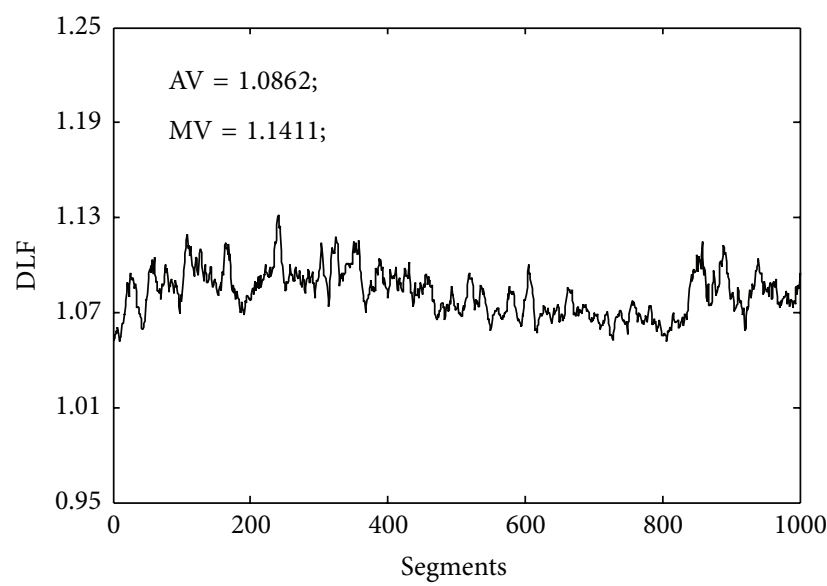

(c) The bottom chord member

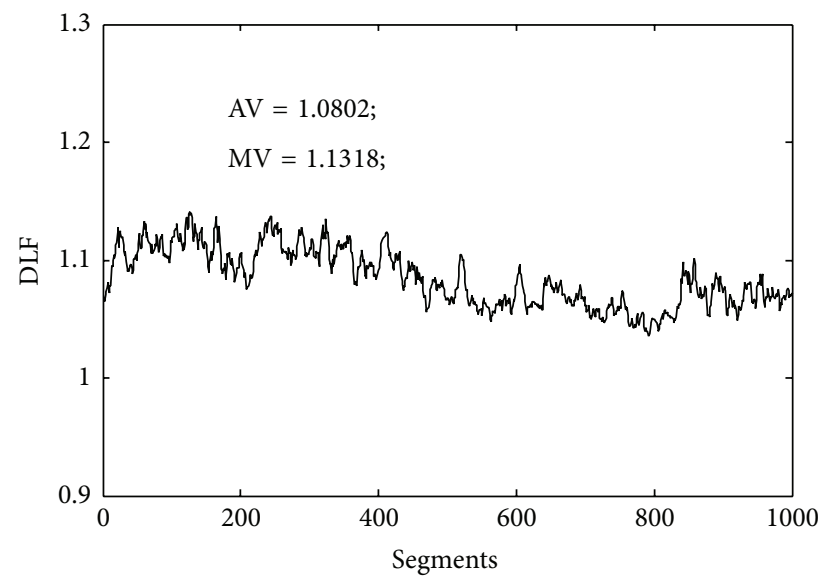

(b) The diagonal web member

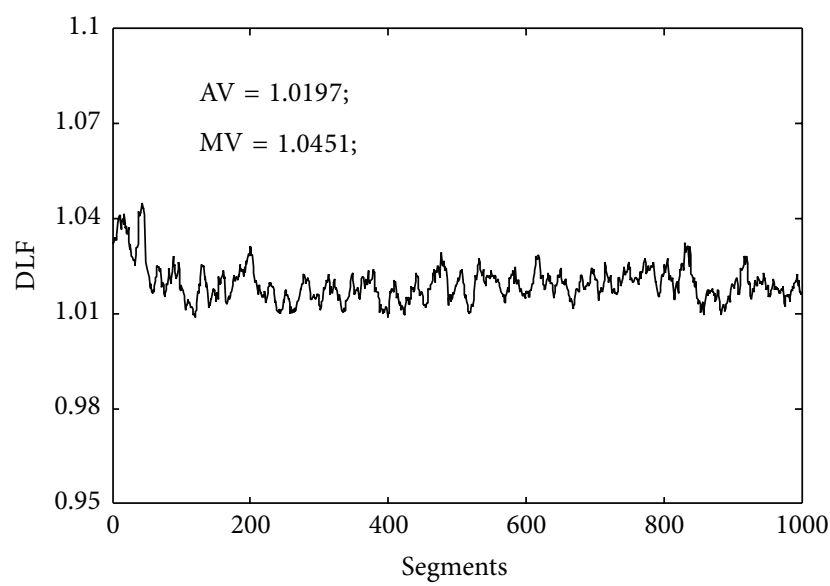

(d) The deck chord member

FIGURE 6: Field monitoring results of DLFs.

TABLE 1: 16 cases for simulating the strain data.

\begin{tabular}{lcccc}
\hline Number of cases & Carriage load $(\mathrm{kN})$ & Load location & Number of carriages & Train speed $(\mathrm{km} / \mathrm{h})$ \\
\hline 1 & 535 & Lane 1 & 8 & 240 \\
2 & 535 & Lane 2 & 8 & 240 \\
3 & 535 & Lane 3 & 8 & 240 \\
4 & 535 & Lane 4 & 8 & 240 \\
5 & 535 & Lane 1 & 8 & 160 \\
6 & 535 & Lane 2 & 8 & 160 \\
7 & 535 & Lane 3 & 8 & 160 \\
8 & 535 & Lane 4 & 16 & 16 \\
9 & 535 & Lane 1 & 16 & 240 \\
10 & 535 & Lane 2 & 16 & 240 \\
11 & 535 & Lane 3 & 16 & 240 \\
12 & 535 & Lane 4 & 16 & 16 \\
13 & 535 & Lane 1 & 16 & 160 \\
15 & Lane 2 & 16 & 160 \\
\hline
\end{tabular}




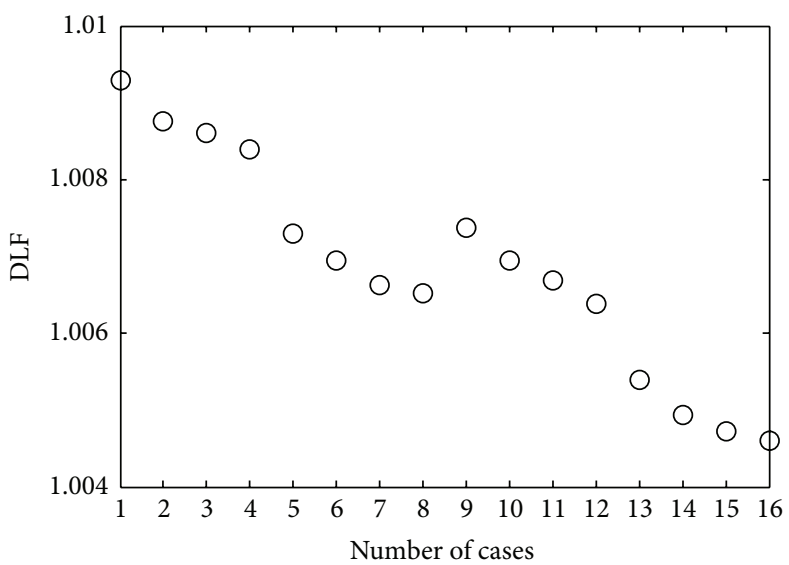

(a) The top chord member

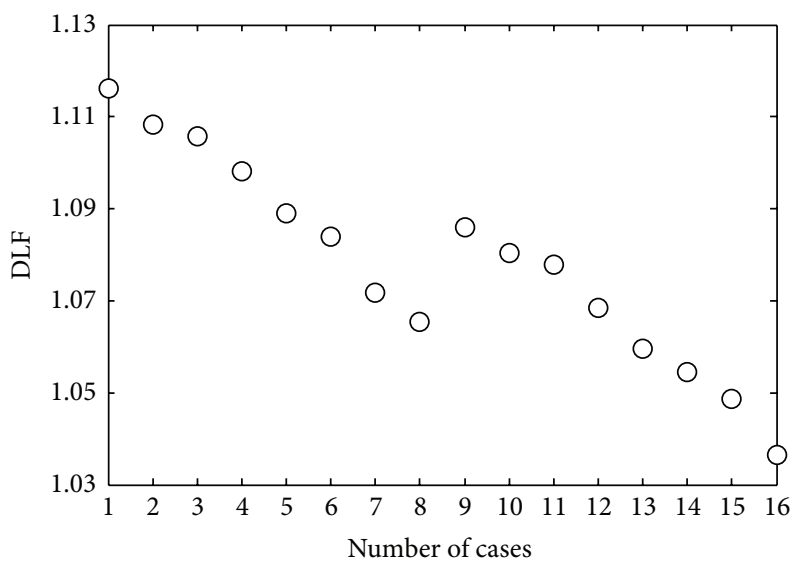

(c) The bottom chord member

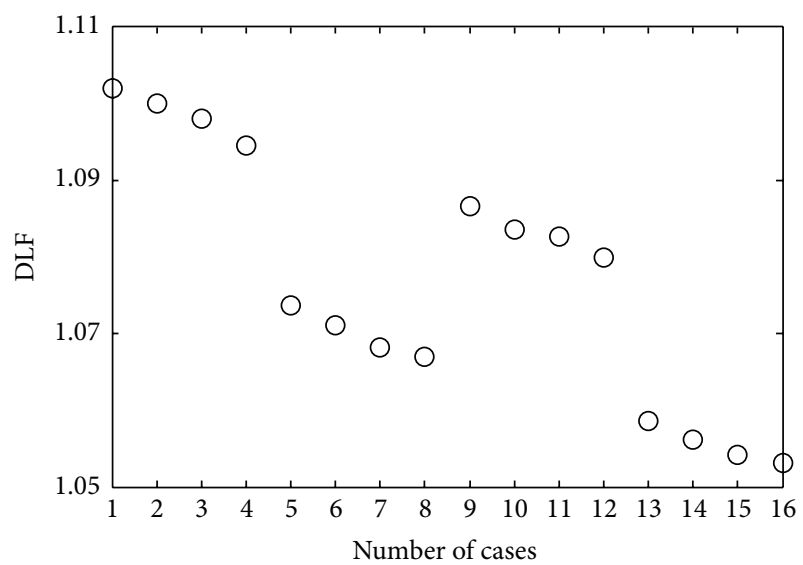

(b) The diagonal web member

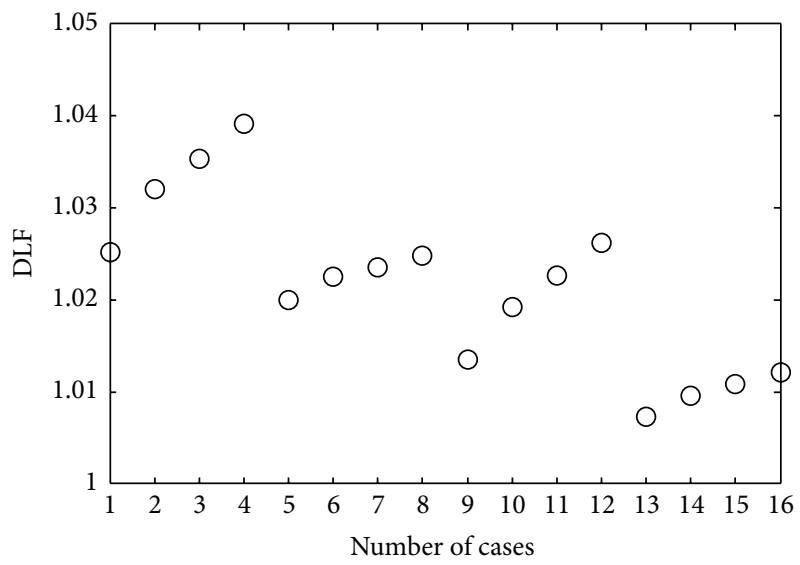

(d) The deck chord member

FIGURE 7: Dynamic load factors for truss 3 using simulated strain responses.

TABLE 2: Monitoring and simulated AVs of the DLFs.

\begin{tabular}{lcccc}
\hline DLFs & The top chord member & The diagonal web member & The bottom chord member & The deck chord member \\
\hline Monitoring AV & 1.0069 & 1.0802 & 1.0862 & 1.0197 \\
Simulated AV & 1.0068 & 1.0768 & 1.0781 & 1.0215 \\
Error (\%) & 0.01 & 0.31 & 0.75 & 0.18 \\
\hline
\end{tabular}

\section{Factors Affecting the Dynamic Load Factors}

As mentioned in the preceding sections, many factors affect the magnitude of the DLF. The influence of lane position of trains, number of train carriages, and speed of trains was studied and is presented in the following sections.

4.1. Lane Position. There are 4 train lanes in the girder of DaShengGuan Bridge, as shown in Figure 2(a). Firstly, the measured DLFs of 1000 trains in Figure 6 are classified as 4 groups corresponding to 4 train lanes, respectively. The total number of the DLFs for each train lane is 250 . Then, for each group the 250 DLFs are divided into 50 segments and the mean value of each segment is computed as shown in Figure 9. Furthermore, the mean values of the simulated DLFs in Figure 7 are computed for each train lane, respectively, which are also shown in Figure 9. $L_{\mathrm{s}, i}$ denotes the average value of the $i$ th train lane, $i=1,2,3,4$. It can be seen that the influence of lane 1 , lane 2 , lane 3 , and lane 4 on the DLFs decreases successively for the top chord member, the diagonal web member, and the bottom chord member but increases successively for the deck chord member. Therefore, with the train closer to the steel truss arch, the dynamic effect is more significant for the deck chord member.

4.2. Number of Train Carriages. In China, the high-speed electric multiple unit (EMU) train has 8 carriages or 16 carriages, respectively. In this study, an investigation has been carried out to determine if there is a correlation between the DLF and the number of train carriages. Firstly, the measured DLFs of 1000 trains in Figure 6 are classified as two groups corresponding to the 8 carriages and 16 carriages, respectively. The total number of the DLFs for both 8 and 16 carriages is 500 . Then, for each group the 500 DLFs are 


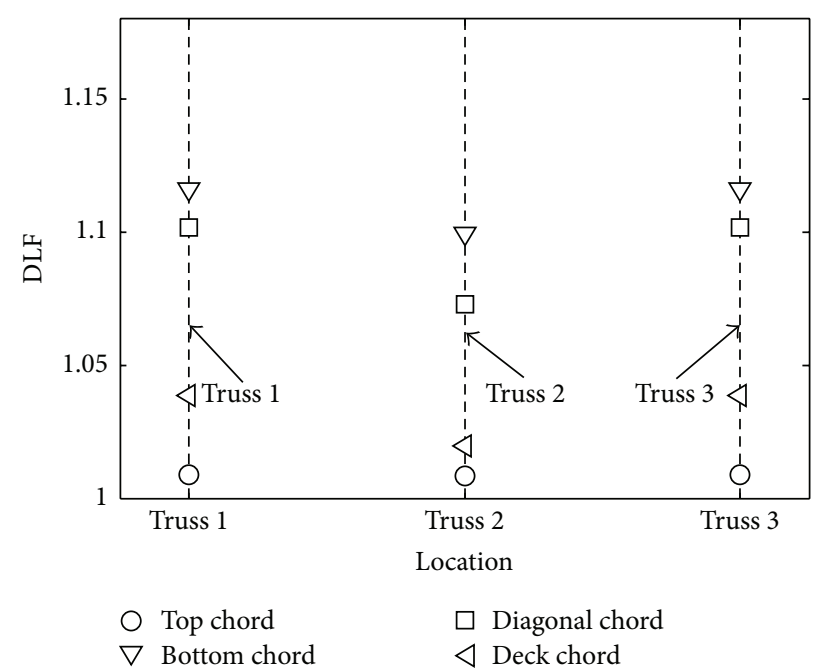

Figure 8: Maximum dynamic load factors for truss 1, truss 2, and truss 3 .

divided into 50 segments and the mean value of each segment is computed as shown in Figure 10. Furthermore, the mean values $C_{s, 8}$ and $C_{s, 16}$ of the simulated DLFs in Figure 7 are computed for 8 and 16 carriages, respectively, which are also shown in Figure 10. The figures show an increase in the mean DLF for the 8 carriages comparing with the 16 carriages. However, it can also be noticed that the absolute value of the increase is very small.

4.3. Speed of Trains. According to the field monitoring results, the speed of trains ranges approximately from $110 \mathrm{~km} / \mathrm{h}$ to $250 \mathrm{~km} / \mathrm{h}$. The results of the DLF (DLF) caused by the speed of trains are plotted in Figure 11. Meanwhile, the simulated DLFs under the speeds of $160 \mathrm{~km} / \mathrm{h}$ and $240 \mathrm{~km} / \mathrm{h}$ are shown in Figure 11, which can verify the influence of train speed on the monitoring DLFs. It can be seen that the speed and DLF are weakly correlated. According to the fitting curves shown in Figure 11, even though the correlation between speed and DLF is not strong, there exists an increasing linear relationship (i.e., as the speed of trains increases, the DLF will also increase).

\section{Statistical Analysis of the Dynamic Load Factors}

5.1. Probability Distribution Model. In this study, a large amount of data on DLFs was acquired through field monitoring. Therefore, it is important to introduce a statistical analysis to obtain the appropriate design value of DLF. Firstly, the accumulative probability function for DLFs is established. Three types of accumulative probability function are selected: the normal distribution, the Weibull distribution, and the Generalized Extreme Value Distribution (GEVD). Taking the DLFs in Figure 6(a), for example, the accumulative probability and fitting curves using three probability distribution functions are shown in Figure 12(a). Their fitting errors are obtained by calculating the variances of residuals between the monitoring curve and the fitting curve, which are 0.000112, 0.000189 , and 0.000105 , respectively. Thus, the GEVD is the best fitting curve, which is defined by

$$
G(D)=\exp \left[-\left[1+r\left(\frac{D-b}{a}\right)\right]^{-1 / r}\right],
$$

where $D$ denotes the DLFs; $r, a$, and $b$ denote shape parameter, scale parameter, and location parameter of GEVD, respectively, which can be estimated by maximum likelihood method. In detail, Generalized Extreme Value Distribution $G(D)$ combines three types of distributions (i.e., Gumbel distribution, Frechet distribution, and Weibull distribution) into a single form. The parameters of GEVD in Figure 12(a) are $r=-0.1279, a=0.0009$, and $b=1.0066$. Moreover, Figures 12(b)-12(d) show the fitting curves of GEVD for the diagonal web member, the bottom chord member, and the deck chord member. It can be seen that the GEVD can well describe the probability characteristics of the DLFs.

\subsection{Evaluation of Dynamic Load Factors}

5.2.1. Standard Value of Dynamic Load Factors. Eurocode 1 [12] specifies that the standard value is the extreme values within 50-year return period. The monitoring dynamic strains are affected by the irregularity of the rail, so the calculated DLF of the monitoring dynamic strains has contained the influence of the irregularity of the rail. The irregularity of the rail may be worse later and furthermore influences the current statistics characteristics of the DLFs, but whether the irregularity of the rail is really worse or not is hard to decide. So this paper studied the case when the irregularity of the rail does not get worse. In this case, the standard value of the monitored data obtained within a short period of time can be used as the extreme value of the DLF within 50-year return period. Specifically, the standard value can be calculated by

$$
\begin{aligned}
& P=1-G\left(D_{\mathrm{p}}\right), \\
& P=\frac{1}{50 N},
\end{aligned}
$$

where $D_{\mathrm{p}}$ denotes the standard value; $P$ denotes the exceeding probability; $N$ denotes the number of DLFs in one year. One LDF can be calculated after one train passes the bridge, so $N$ is equal to the total amount of trains passing the bridge in one year. On consideration that $D_{\mathrm{p}}$ cannot be directly calculated by ( $9 \mathrm{a})$ and $(9 \mathrm{~b})$, then $D_{\mathrm{p}}$ is numerically calculated by Newton iteration formula as follows:

$$
D_{\mathrm{p}}^{n+1}=D_{\mathrm{p}}^{n}+\frac{1-G\left(D_{\mathrm{p}}^{n}\right)-P}{G^{\prime}\left(D_{\mathrm{p}}^{n}\right)},
$$

where $D_{\mathrm{p}}^{n}$ is the $n$th iteration of $D_{\mathrm{p}}^{0}$, and $G^{\prime}\left(D_{\mathrm{p}}^{n}\right)$ is the oneorder derivative function of $G\left(D_{\mathrm{p}}^{n}\right)$. Iteration terminates when the absolute difference between $D_{\mathrm{p}}^{n+1}$ and $D_{\mathrm{p}}^{n}$ is less than 0.0005. Based on the method above, the stand values of DLFs are shown in Table 3 . It can be seen that the bottom chord has 


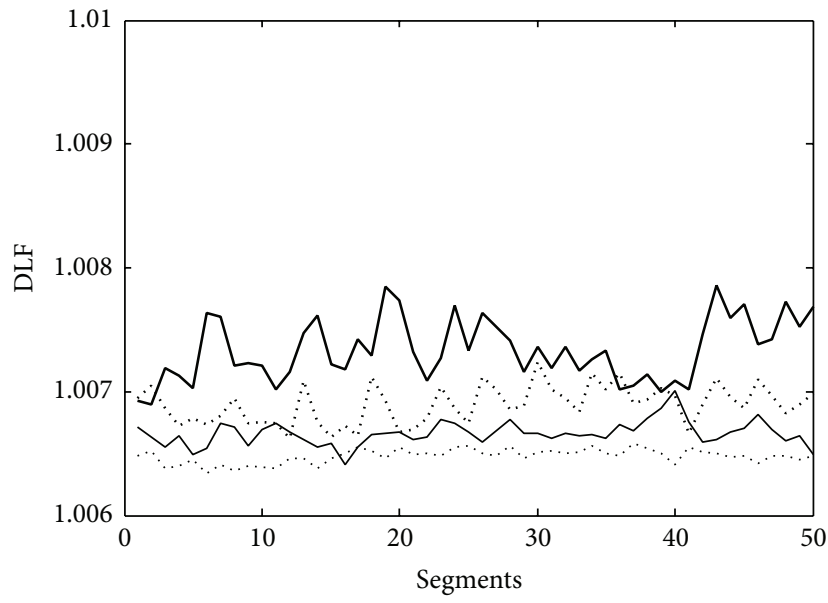

$\begin{array}{llll}\text { — Lane } 1 L_{\mathrm{s}, 1}=1.0073 ; & - & \text { Lane } 3 L_{\mathrm{s}, 3}=1.0067 ; \\ \ldots . . . & \text { Lane } 2 L_{\mathrm{s}, 2}=1.0069 ; & \ldots \ldots & \text { Lane } 4 L_{\mathrm{s}, 4}=1.0065 ;\end{array}$

(a) The top chord member

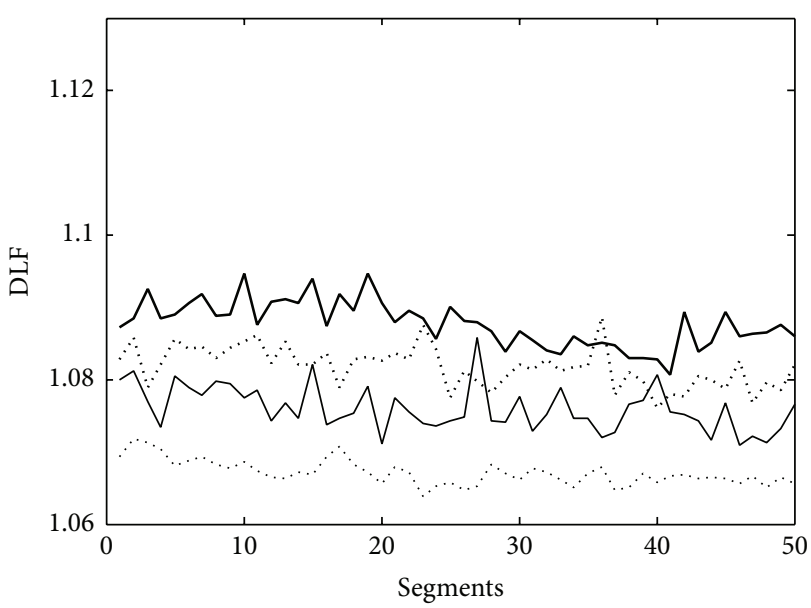

- Lane $1 L_{\mathrm{s}, 1}=1.0877 ; \quad$ Lane $3 L_{\mathrm{s}, 3}=1.0760$;

…. Lane $2 L_{\mathrm{s}, 2}=1.0818 ; \quad \cdots .$. Lane $4 L_{\mathrm{s}, 4}=1.0671$;

(c) The bottom chord member

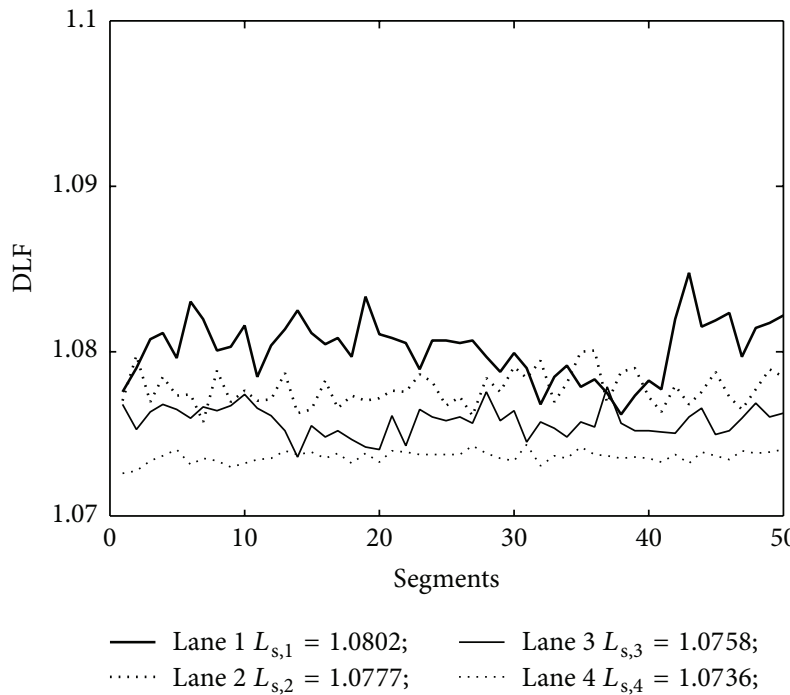

(b) The diagonal web member

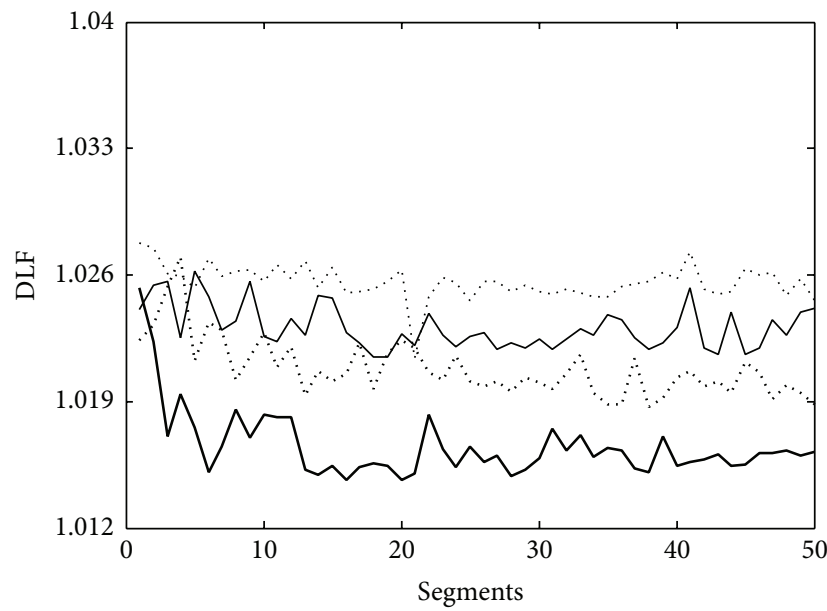

- Lane $1 L_{\mathrm{s}, 1}=1.0877 ; \quad$ Lane $3 L_{\mathrm{s}, 3}=1.0760$;

…. Lane $2 L_{\mathrm{s}, 2}=1.0818 ; \quad \cdots .$. Lane $4 L_{\mathrm{s}, 4}=1.0671$;

(d) The deck chord member

Figure 9: The influence of train lanes on the mean DLF.

TABLE 3: Stand values of dynamic load factors.

\begin{tabular}{lcccc}
\hline Member type & The top chord member & The diagonal web member & The bottom chord member & The deck chord member \\
\hline Standard value & 1.0115 & 1.1376 & 1.1613 & 1.0549 \\
\hline
\end{tabular}

the maximum stand value 1.1613. Moreover, the maximum value of the DLFs in Figure 6 for each structural member is computed and the correlation between standard values and maximum values is shown in Figure 13. The fitting curves and the corresponding parameters of linear correlations are shown in Figure 13 using the least square method, where $k$ denotes slope term and denotes the constant term. It can be seen that the correlation shows obvious linear correlation.

\subsubsection{Comparison with Different Bridge Design Codes}

(1) The Manual for Railway Engineering (USA). According to the Manual for Railway Engineering [13], the DLF for steel bridges can be defined as follows:

$$
\mathrm{DLF}=1+\mu
$$




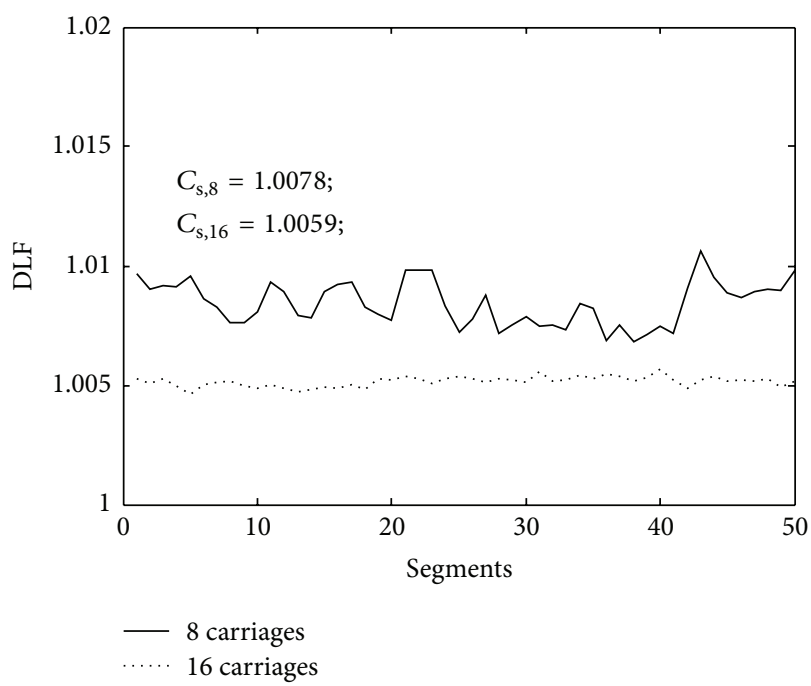

(a) The top chord member

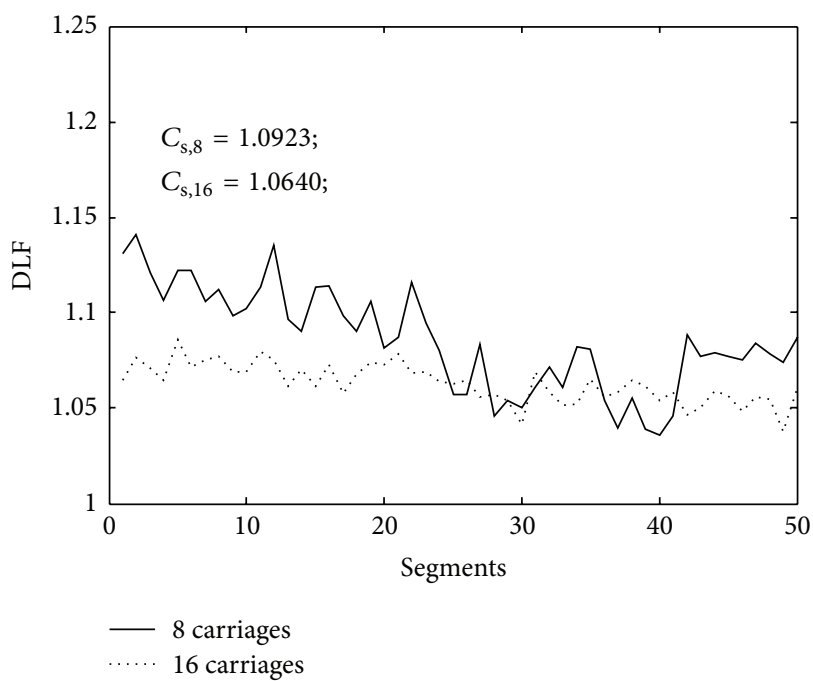

(c) The bottom chord member

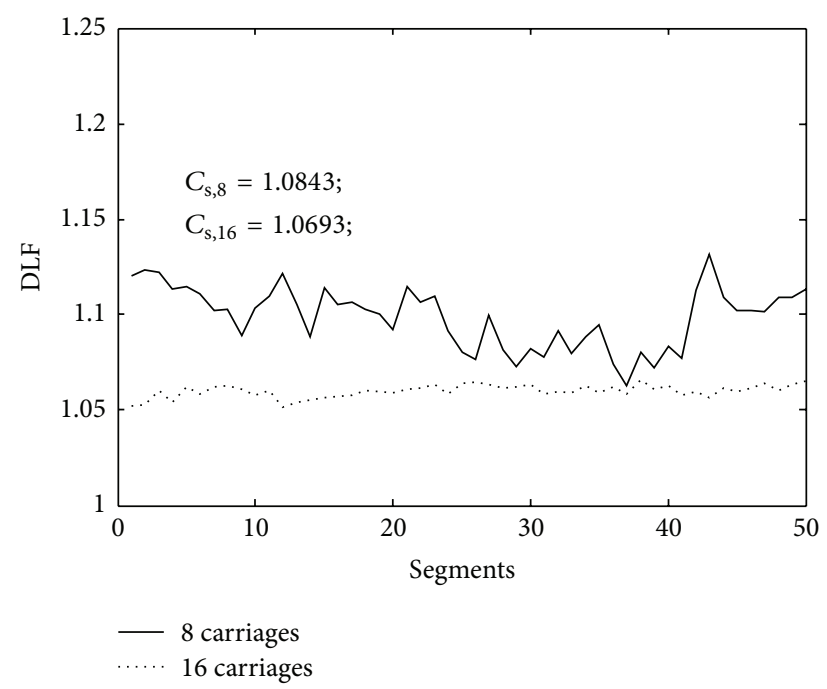

(b) The diagonal web member

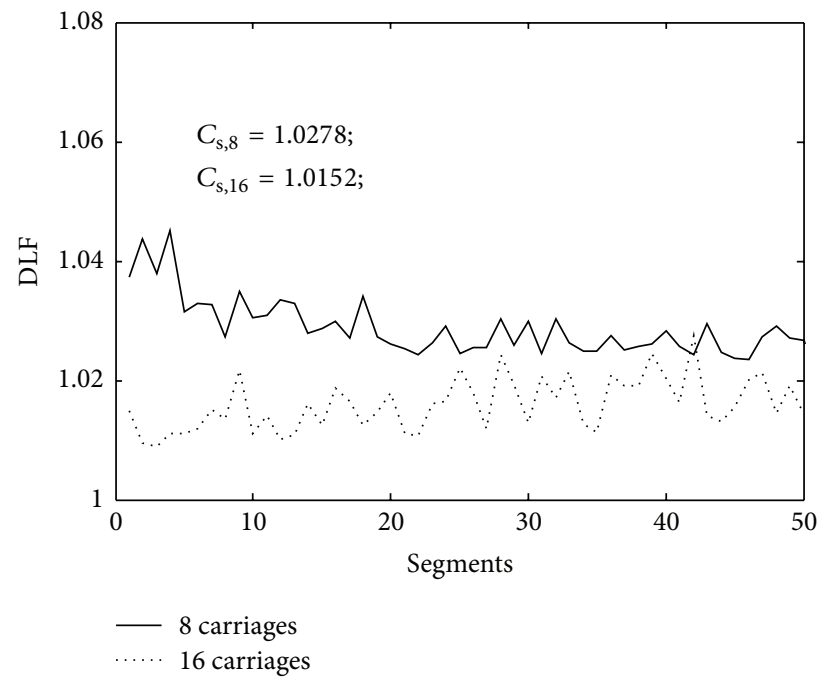

(d) The deck chord member

FiguRE 10: Number of train carriages versus mean DLF.

and if $L<24.4 \mathrm{~m}$,

$$
\mu=\frac{0.3}{S}+0.4-\frac{L^{2}}{500}
$$

and if $L \geqslant 24.4 \mathrm{~m}$,

$$
\mu=\frac{0.3}{S}+0.16+\frac{1.83}{L-0.94},
$$

where $L$ denotes the span length and $S$ denotes the bridge width.

(2) The UIC Code 776-IR. According to the UIC Code 776IR [14], if the railway bridges are designed by the UIC load diagram, then the DLF can be defined as follows:

$$
\mathrm{DLF}_{1}=\frac{0.96}{\sqrt{L_{\theta}}-0.2}+0.88
$$

$$
\begin{aligned}
& \mathrm{DLF}_{2}=\frac{1.44}{\sqrt{L_{\theta}}-0.2}+0.82 \\
& \mathrm{DLF}_{3}=\frac{2.16}{\sqrt{L_{\theta}}-0.2}+0.76
\end{aligned}
$$

where $\mathrm{DLF}_{1}, \mathrm{DLF}_{2}$, and $\mathrm{DLF}_{3}$ denote three kinds of DLFs and $L_{\theta}$ denotes the loading length. If $\mathrm{DLF}_{1}, \mathrm{DLF}_{2}$, and $\mathrm{DLF}_{3}$ are less than 1.0, then $\mathrm{DLF}_{1}, \mathrm{DLF}_{2}$, and $\mathrm{DLF}_{3}$ take the value 1.0. The code specifies that, for railway lanes under good maintenance, $\mathrm{DLF}_{1}$ is used to calculate the DLF of shearing force, and $\mathrm{DLF}_{2}$ is used to calculate the DLF of bending movement; for other railway lanes, $\mathrm{DLF}_{2}$ is used to calculate the DLF of shearing force, and $\mathrm{DLF}_{3}$ is used to calculate the DLF of bending movement.

(3) BSI-BS5400. According to the BSI-BS5400 [15], the DLF of the high-speed railway coaches is 1.2 when it is used to 


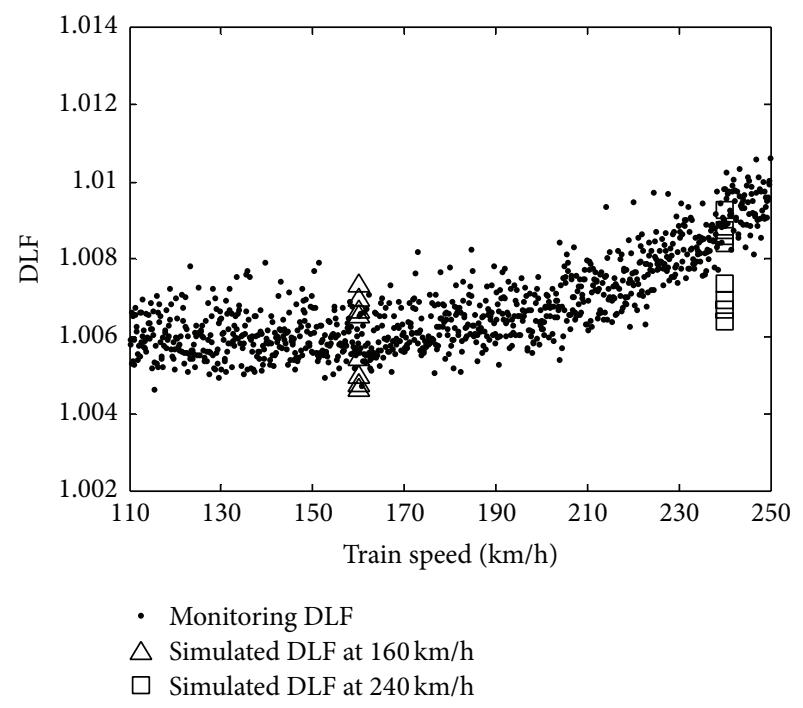

(a) The top chord member

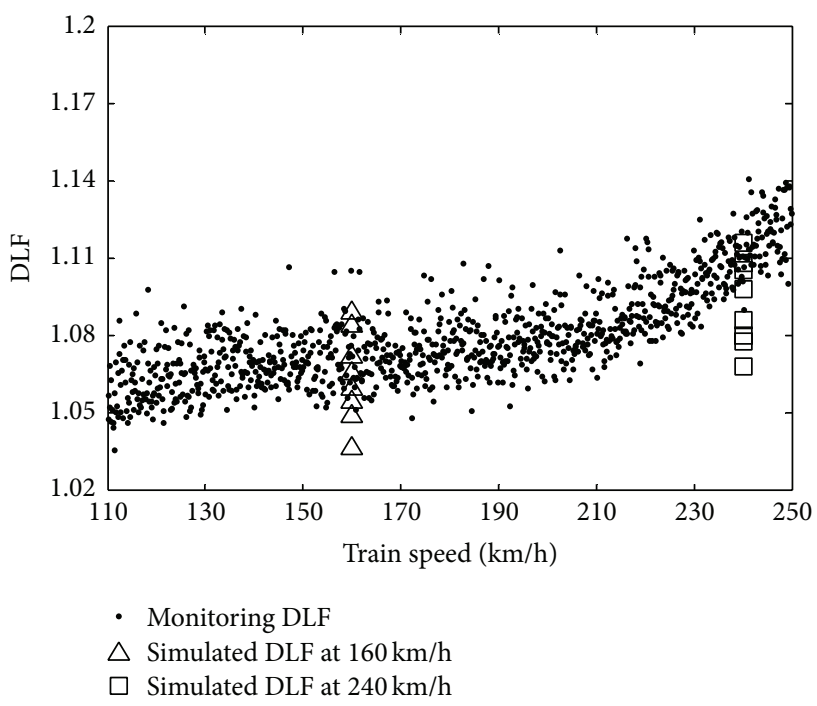

(c) The bottom chord member

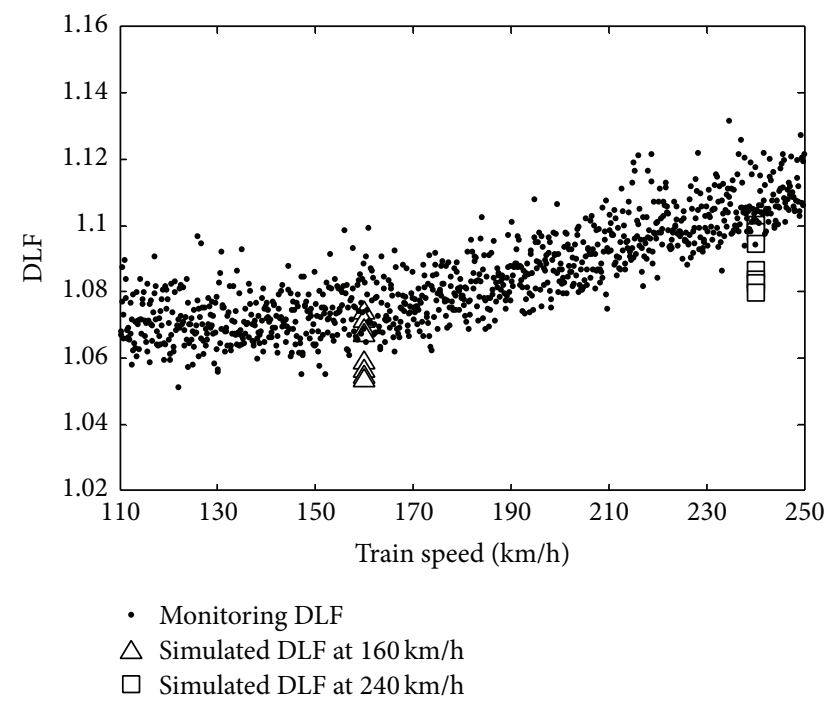

(b) The diagonal web member

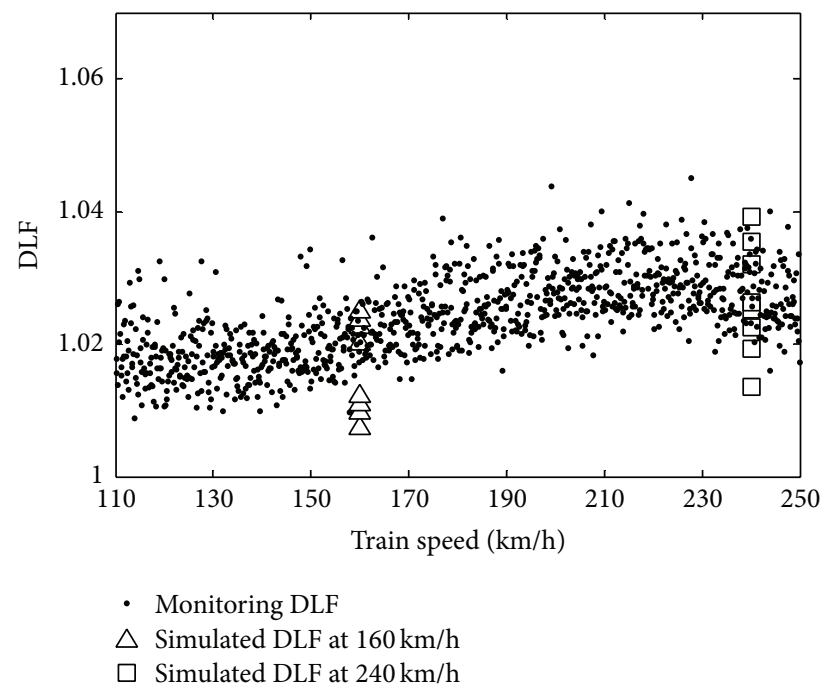

(d) The deck chord member

FIGURE 11: Speed of trains versus DLF.

calculate the bending movement and the shearing force. But for railways without ballast groove, the longitudinal girder for directly bearing the railway load, and the transverse girder of single-track railway, the DLF should be 1.4.

(4) Fundamental Code for Design on Railway Bridge and Culvert (China). According to the fundamental code for design on railway bridge and culvert in China [16], the DLF for continuous steel bridges is defined as follows:

$$
\mathrm{DLF}=1+\frac{28}{40+L}
$$

But if the train speed exceeds $200 \mathrm{~km} / \mathrm{h}$, according to the temporary regulation on the latest design of $200 \mathrm{~km} \sim 250 \mathrm{~km}$ special railway for passengers [17], the DLF for continuous steel bridges is defined as follows:

$$
\begin{aligned}
& \mathrm{DLF}_{4}=\frac{0.996}{\sqrt{L_{\varphi}}-0.2}+0.913 \\
& \mathrm{DLF}_{5}=\frac{1.494}{\sqrt{L_{\varphi}}-0.2}+0.851
\end{aligned}
$$

where $\mathrm{DLF}_{4}$ and $\mathrm{DLF}_{5}$ denote the DLFs for shearing force and bending movement, respectively, and if $\mathrm{DLF}_{4}$ and $\mathrm{DLF}_{5}$ are less than 1.0, then $\mathrm{DLF}_{4}$ and $\mathrm{DLF}_{5}$ take the value 1.0; $L_{\varphi}$ denotes the loading length. Specifically, $L_{\varphi}$ is calculated by

$$
L_{\varphi}=\lambda \frac{1}{N} \sum_{n=1}^{N} W_{n}
$$




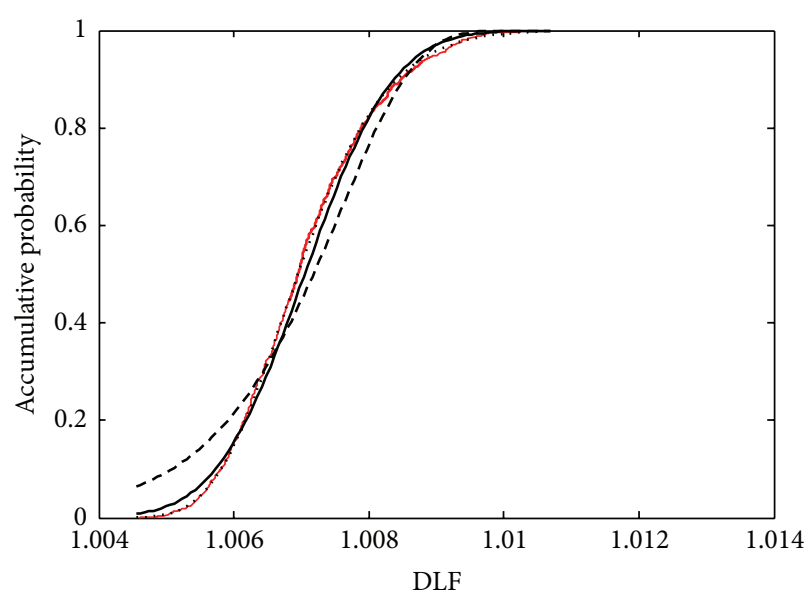

- The monitoring curve --- The Weibull distribution — The normal distribution ….. The GEVD

(a) The top chord member

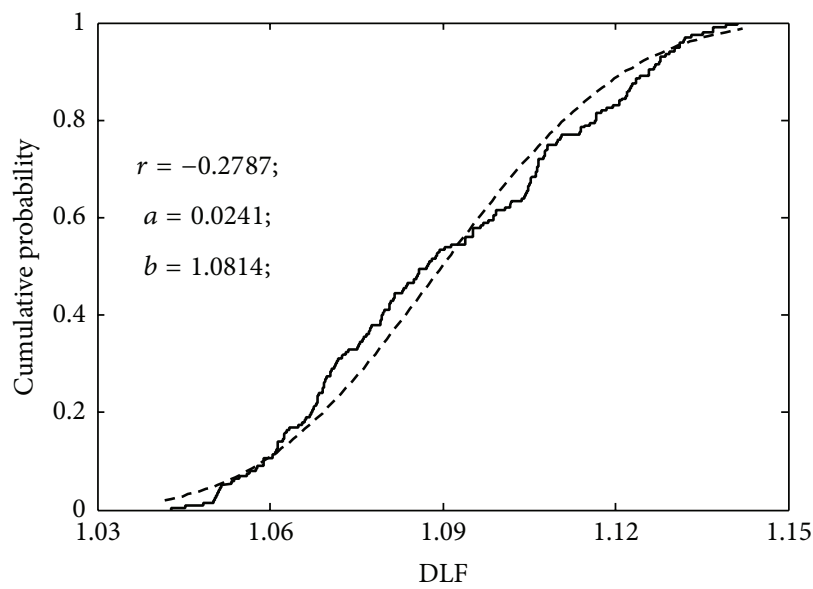

- Monitoring curve

- - Fitting GEVD

(c) The bottom chord member

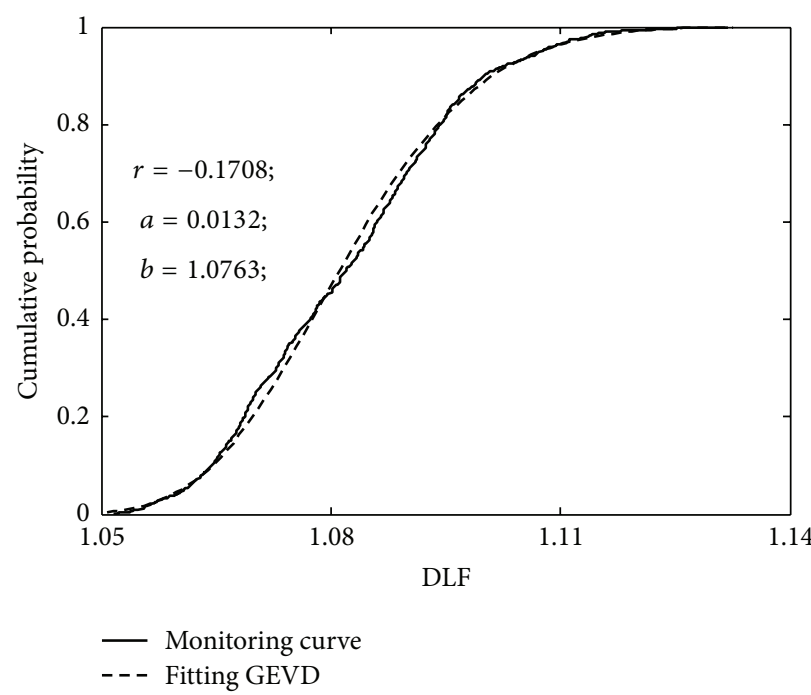

(b) The diagonal web member

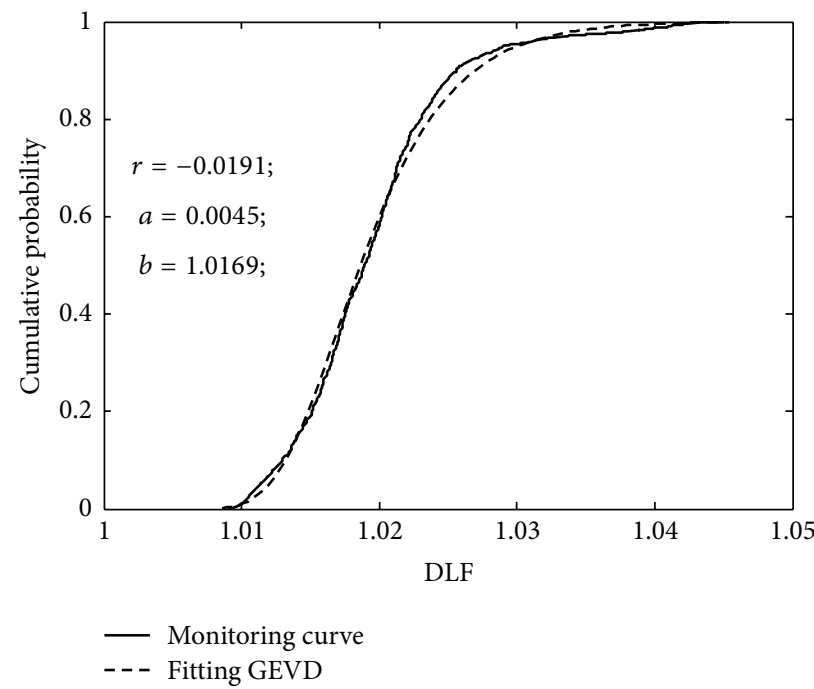

(d) The deck chord member

Figure 12: The accumulative probability and its fitting curves.

where $\lambda$ is the reduction factor, and

$$
\text { if } \begin{aligned}
N & =1, \\
\lambda & =1.0 ; \\
\text { if } N & =2, \\
\lambda & =1.2 ; \\
\text { if } N & =3, \\
\lambda & =1.3 ; \\
\text { if } N & =4, \\
\lambda & =1.4 ; \\
\text { if } N & \geqslant 5, \\
\lambda & =1.5 ;
\end{aligned}
$$

$N$ denotes the number of spans; $W_{n}$ denotes the length of the $i$ th span. Moreover, if $L_{\varphi}<3.61 \mathrm{~m}, L_{\varphi}=3.61 \mathrm{~m}$; if $L_{\varphi}$ is less than the maximum span, $L_{\varphi}$ takes the value of the maximum span.

(5) DS804 (Germany). According to the DS804 code in Germany [18], the UIC load diagram is used to be the design load, and the DLF is defined by the following:

if $L \leqslant 3.61 \mathrm{~m}$,

$$
\text { DLF }=1.67
$$

and if $3.61 \mathrm{~m}<L<65 \mathrm{~m}$,

$$
\mathrm{DLF}=0.82+\frac{1.44}{\sqrt{L}-0.2}
$$


TABLE 4: Summary of dynamic load factors according to different bridge design codes.

\begin{tabular}{|c|c|c|c|c|c|c|}
\hline Code & USA code & UIC code & BSI-BS5400 & China code & DS804 code & JNR code \\
\hline DLF & 1.1755 & $\begin{array}{l}\mathrm{DLF}_{1}=1.0 ; \\
\mathrm{DLF}_{2}=1.0 ; \\
\mathrm{DLF}_{3}=1.0\end{array}$ & 1.2 & $\begin{array}{l}\mathrm{DLF}_{4}=1.0 \\
\mathrm{DLF}_{5}=1.0\end{array}$ & 1.0 & 1.1124 \\
\hline
\end{tabular}

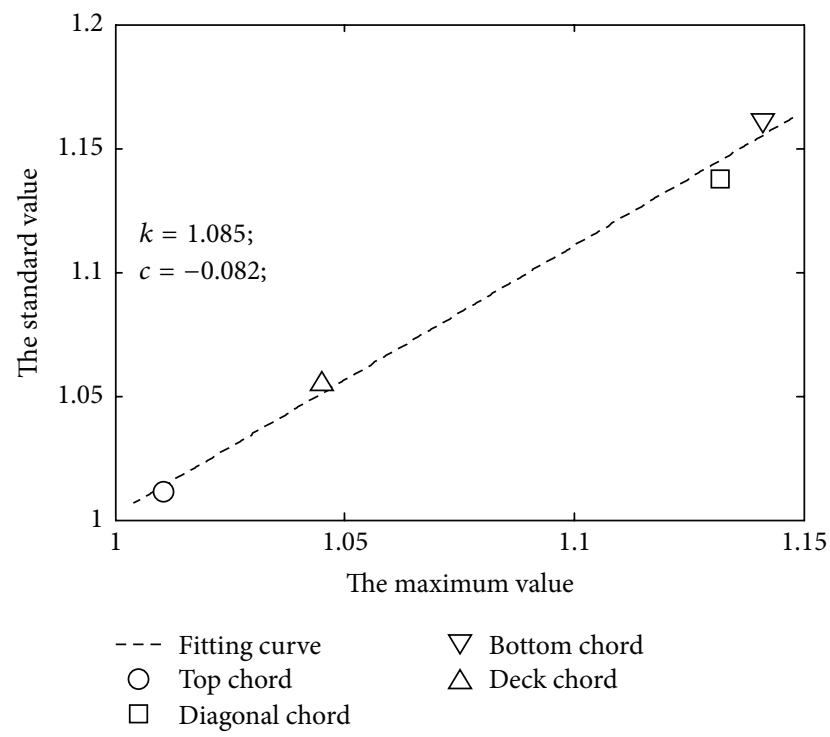

FIGURE 13: Correlation between standard values and maximum values of DLF.

and if $L \geqslant 65 \mathrm{~m}$,

$$
\mathrm{DLF}=1.0
$$

(6) JNR (Japan). According to the JNR code in Japan [19], the DLF of steel bridge is defined by

$$
\begin{aligned}
\text { DLF } & =1+\mu, \\
\mu & =\frac{10}{65+L}+\frac{0.52}{L^{0.2}}, \\
\mu_{\max } & =0.7 ;
\end{aligned}
$$

for the double track railway, the DLF should multiply the reduction factor $\alpha$ :

$$
\text { if } L \leqslant 80 \mathrm{~m} \text {, }
$$

$$
\alpha=1-\frac{L}{200}
$$

and if $L>80 \mathrm{~m}$,

$$
\alpha=0.6
$$

Table 3 summarizes the dynamic load factors according to different bridge design codes. By comparing the DLFs in Tables 2 and 4, it can be noticed that the maximum DLF obtained from the present study, which is 1.1613 , is close to the specified values in the USA code and BSI-BS5400 code. And UIC Code, China code, and DS804 code are found to be the most unsafe in deriving the value of the DLF for design purposes.

\section{Conclusions}

In this study, an evaluation of dynamic load factors for a high-speed railway truss arch bridge was carried out using the monitoring strain data and finite element simulation. On the basis of the results obtained from this particular study the following conclusions, which can provide reference for similar kinds of bridges, can be drawn:

(1) For each plane of steel truss arch, the dynamic load factors (DLFs) decrease in turn in the bottom chord member, diagonal web member, deck chord member, and top chord member. Furthermore, for three planes of truss arch, the dynamic effects induced by highspeed trains for middle truss arch are less than those for side truss arch.

(2) Strong correlations were found between the train lane and the DLF. With the train lane closer to the side truss arch, the DLF is larger for the deck chord member and smaller for the top chord member, diagonal web member, and bottom chord member.

(3) The mean DLF obtained from trains with 8 carriages in a given sensor location was found to be larger than the mean DLF obtained from trains with 16 carriages. However, it can also be noticed that the absolute value of the increase is very small.

(4) Even though weak correlations were found between the speed of trains and the DLFs, there exists an increasing linear relationship (i.e., as the speed of trains increases the DLF will also increase).

(5) The Generalized Extreme Value Distribution can well describe the probability characteristics of the DLFs, based on which the standard values of DLFs within 50 -year return period are evaluated and are close to the specified values in the USA code and BSI-BS5400 code.

\section{Competing Interests}

The authors declare that there is no conflict of interests regarding the publication of this paper. 


\section{Acknowledgments}

The authors gratefully acknowledge the National Basic Research Program of China (973 Program) (no. 2015CB060000), the National Natural Science Foundation of China (no. 51438002 and no. 51578138), the Fundamental Research Funds for the Central Universities (no. 2242016K41066), the Innovation Plan Program for Ordinary University Graduates of Jiangsu Province in 2014 (no. KYLX_0156), and the Scientific Research Foundation of Graduate School of Southeast University (no. YBJJ1441).

\section{References}

[1] P. Paultre, O. Chaallal, and J. Proulx, "Bridge dynamics and dynamic amplification factors-a review of analytical and experimental findings," Canadian Journal of Civil Engineering, vol. 19, no. 2, pp. 260-278, 1992.

[2] D. L. McLean and M. L. Marsh, "Dynamic impact factors for bridges," NCHRP Synthesis 266, Transportation Research Board, Washington, DC, USA, 1998.

[3] L. Deng, C. S. Cai, and M. Barbato, "Reliability-based dynamic load allowance for capacity rating of prestressed concrete girder bridges," Journal of Bridge Engineering, vol. 16, no. 6, pp. 872880, 2011.

[4] L. Ding, H. Hao, and X. Zhu, "Evaluation of dynamic vehicle axle loads on bridges with different surface conditions," Journal of Sound and Vibration, vol. 323, no. 3-5, pp. 826-848, 2009.

[5] B. A. Demeke, H. T. C. Tommy, and Y. Ling, "Evaluation of dynamic loads on a skew box girder continuous bridge Part I: field test and modal analysis," Engineering Structures, vol. 29, no. 6, pp. 1064-1073, 2007.

[6] H. H. Nassif and A. S. Nowak, "Dynamic load for girder bridges under normal traffic," Archives of Civil Engineering, vol. 42, no. 4, pp. 381-400, 1997.

[7] A. Miyamoto, "Field tests for remaining life and load carrying capacity assessment of concrete bridges," in Bridge Maintenance, Safety, Management, Resilience and Sustainability: Proceedings of the Sixth International IABMAS Conference, Stresa, Lake Maggiore, Italy, 8-12 July 2012, pp. 157-164, CRC Press, New York, NY, USA, 2012.

[8] Y. S. Park, D. K. Shin, and T. J. Chung, "Influence of road surface roughness on dynamic impact factor of bridge by full-scale dynamic testing," Canadian Journal of Civil Engineering, vol. 32, no. 5, pp. 825-829, 2005.

[9] C. C. Caprani, "Lifetime highway bridge traffic load effect from a combination of traffic states allowing for dynamic amplification," Journal of Bridge Engineering, vol. 18, no. 9, pp. 901-909, 2013.

[10] L. Deng and C. S. Cai, "Development of dynamic impact factor for performance evaluation of existing multi-girder concrete bridges," Engineering Structures, vol. 32, no. 1, pp. 21-31, 2010.

[11] B. Bakht and S. G. Pinjarkar, "Dynamic testing of highway bridges-a review," Transportation Research Record, vol. 1223, pp. 93-100, 1989.

[12] Eurocode, "The European standard en. Eurocode 1: action on structures," 1991.

[13] The American Railway Engineering and Maintenance of Way Association, Manual for Railway Engineering, 2003.

[14] UIC, Loads to Be Considered in Railway Bridge Design, UIC Code 776-IR, UIC, Paris, France, 4th edition, 1994.
[15] BSI, "Steel, concrete and composite bridge," Tech. Rep. BSIBS5400, 1978.

[16] TB10002.1-2005, "Fundamental code for design on railway bridge and culvert," 2005.

[17] The Ministry of Railways, The Temporary Regulation on the Latest Design of $200 \mathrm{~km} \sim 250 \mathrm{~km}$ Special Railway for Passengers, The Ministry of Railways, 2007 (Chinese).

[18] DS804, Vorschrift fur Eisenbahn Brucken and Sontige Ingenieur Bauwerke, 1993 (German).

[19] Japan Road Association (JNR), Specifications for Highway Bridges, 1978 (Japanese). 


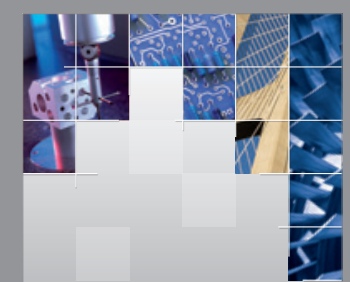

\section{Enfincering}
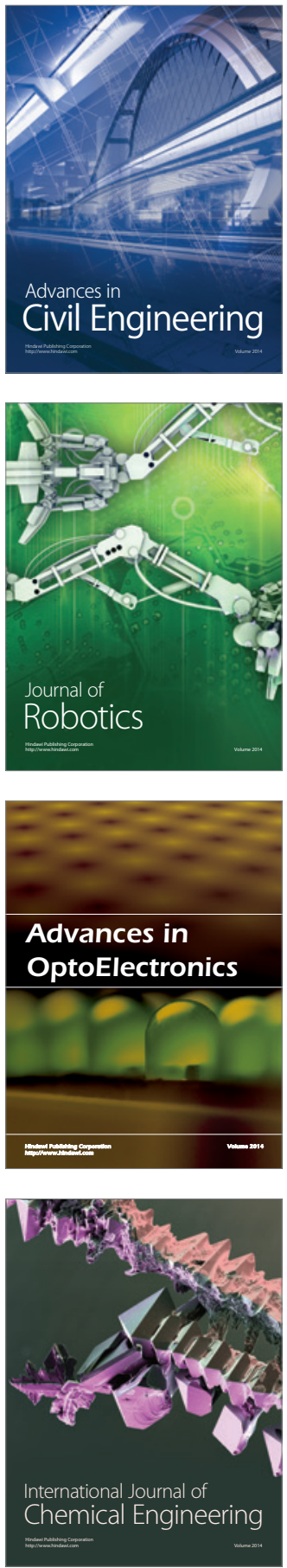

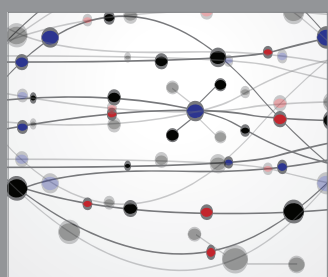

The Scientific World Journal

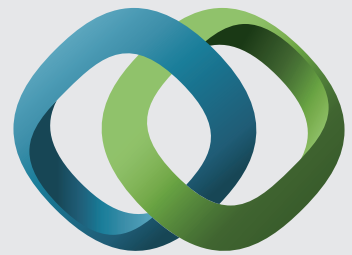

\section{Hindawi}

Submit your manuscripts at

http://www.hindawi.com
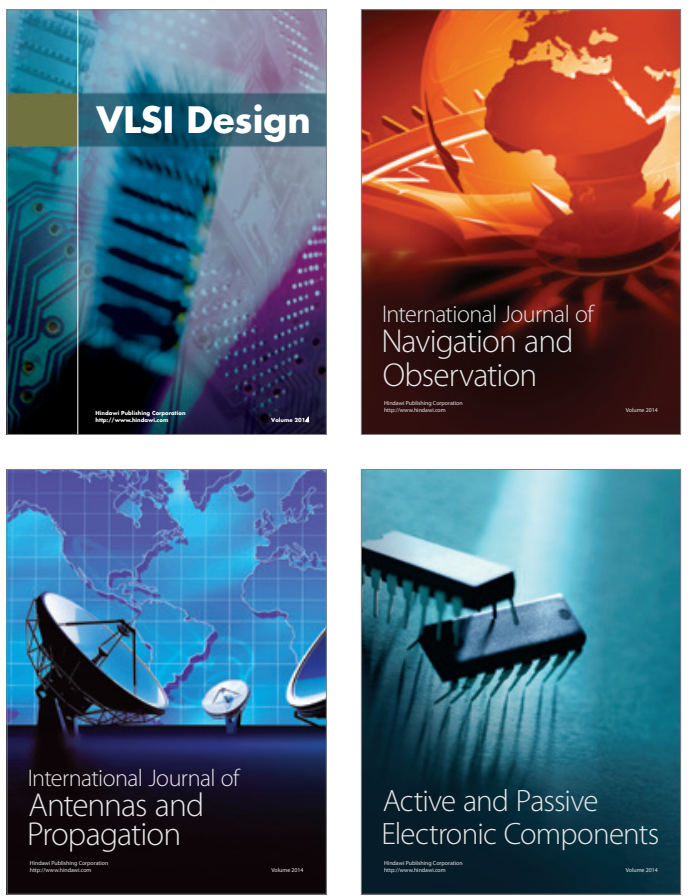
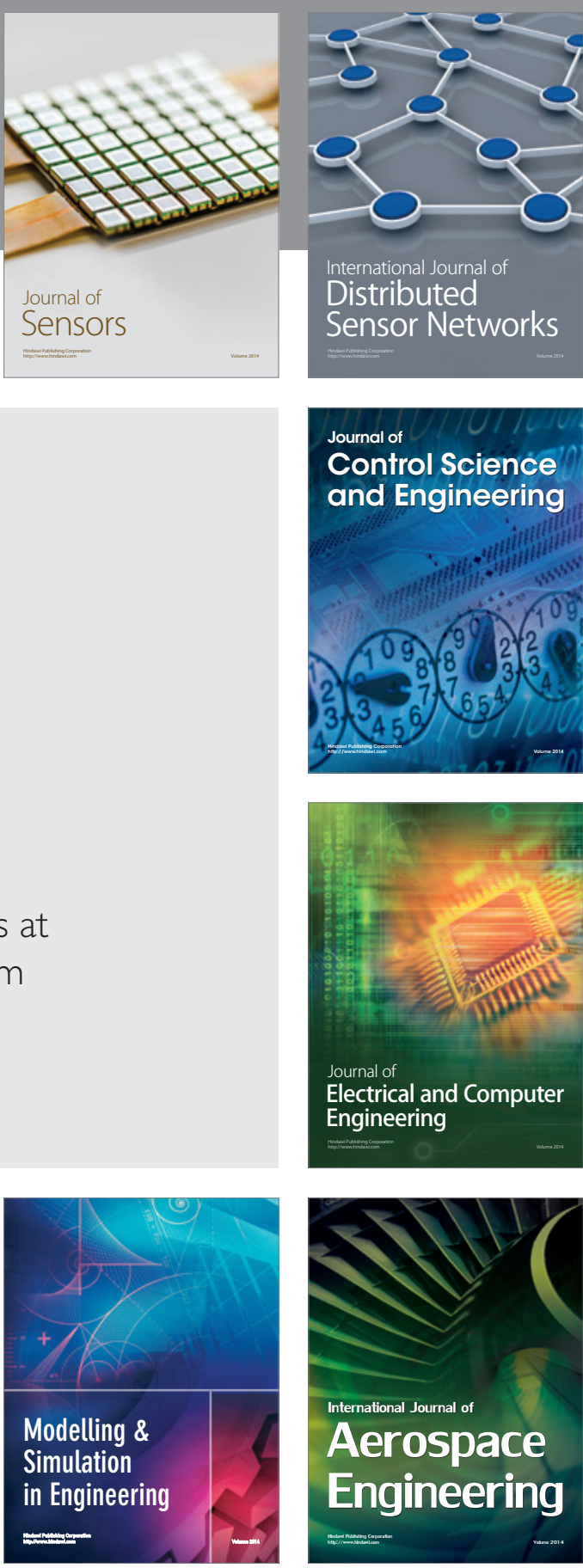

International Journal of

Distributed

Sensor Networks

Journal of

Control Science

and Engineering
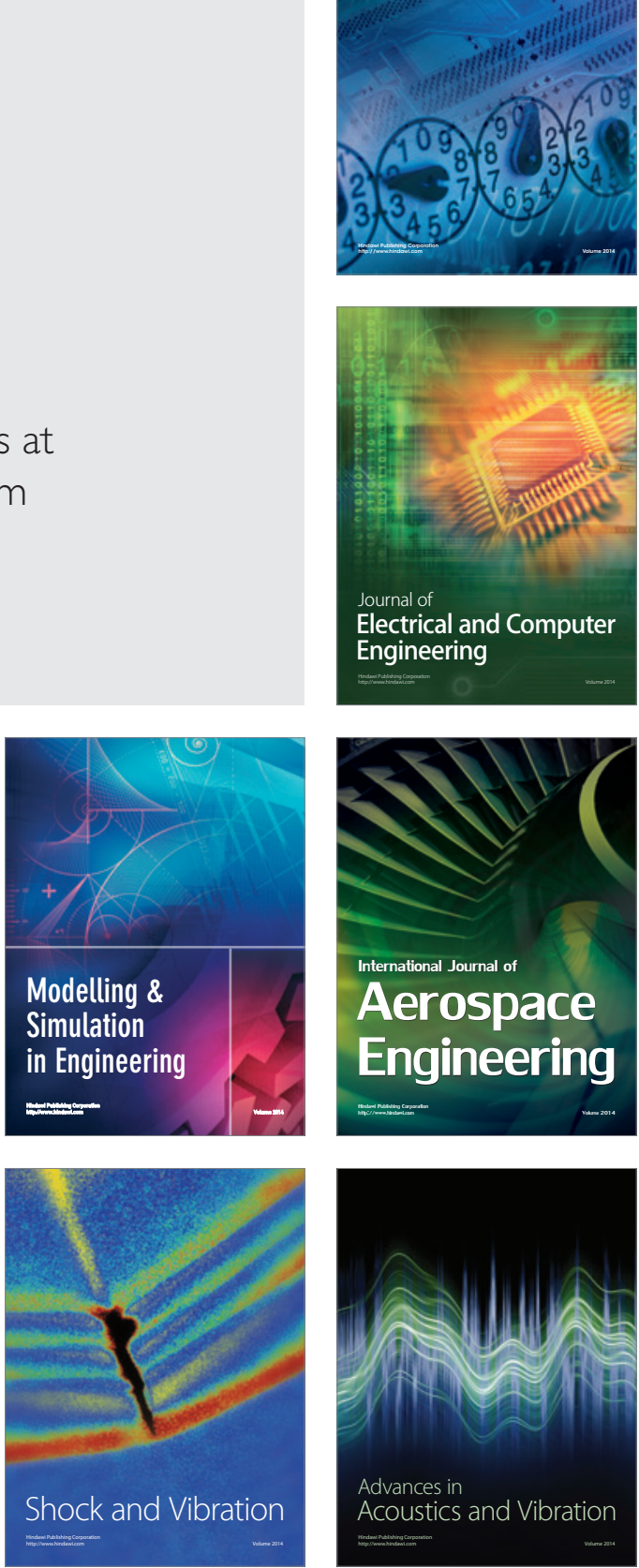